\title{
Article \\ Combining OSMAC Approach and Untargeted Metabolomics for the Identification of New Glycolipids with Potent Antiviral Activity Produced by a Marine Rhodococcus
}

\author{
Fortunato Palma Esposito ${ }^{1}$ (D), Rosa Giugliano ${ }^{2}$ (D), Gerardo Della Sala ${ }^{1}$ (D), Giovanni Andrea Vitale ${ }^{1}$,

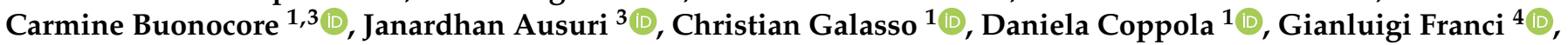 \\ Massimiliano Galdiero ${ }^{2}$ (D) and Donatella de Pascale ${ }^{1,3, *}$
}

1 Department of Marine Biotechnology Stazione Zoologica Anton Dohrn, Villa Comunale, 80121 Naples, Italy; fortunato.palmaesposito@szn.it (F.P.E.); gerardo.dellasala@szn.it (G.D.S.); giovanniandrea.vitale@szn.it (G.A.V.); carmine.buonocore@szn.it (C.B.); christian.galasso@szn.it (C.G.); daniela.coppola@szn.it (D.C.)

2 Department of Experimental Medicine, University of Campania “Luigi Vanvitelli", 80138 Naples, Italy; rosa.giugliano@unicampania.it (R.G.); massimiliano.galdiero@unicampania.it (M.G.)

3 Institute of Biochemistry and Cell Biology, National Research Council, 80131 Naples, Italy; janardhan.ausuri@ibbc.cnr.it

check for updates

Citation: Palma Esposito, F.; Giugliano, R.; Della Sala, G.; Vitale, G.A.; Buonocore, C.; Ausuri, J.; Galasso, C.; Coppola, D.; Franci, G. Galdiero, M.; et al. Combining OSMAC Approach and Untargeted Metabolomics for the Identification of New Glycolipids with Potent Antiviral Activity Produced by a Marine Rhodococcus. Int. J. Mol. Sci. 2021, 22, 9055. https://doi.org/ $10.3390 /$ ijms 22169055

Academic Editor:

Jesus Simal-Gandara

Received: 19 July 2021

Accepted: 19 August 2021

Published: 22 August 2021

Publisher's Note: MDPI stays neutral with regard to jurisdictional claims in published maps and institutional affiliations.

Copyright: (C) 2021 by the authors. Licensee MDPI, Basel, Switzerland. This article is an open access article distributed under the terms and conditions of the Creative Commons Attribution (CC BY) license (https:// creativecommons.org/licenses/by/ $4.0 /)$
4 Department of Medicine, Surgery and Dentistry "Scuola Medica Salernitana", University of Salerno, 84081 Baronissi, Italy; gfranci@unisa.it

* Correspondence: donatella.depascale@szn.it

\begin{abstract}
Natural products of microbial origin have inspired most of the commercial pharmaceuticals, especially those from Actinobacteria. However, the redundancy of molecules in the discovery process represents a serious issue. The untargeted approach, One Strain Many Compounds (OSMAC), is one of the most promising strategies to induce the expression of silent genes, especially when combined with genome mining and advanced metabolomics analysis. In this work, the whole genome of the marine isolate Rhodococcus sp. I2R was sequenced and analyzed by antiSMASH for the identification of biosynthetic gene clusters. The strain was cultivated in 22 different growth media and the generated extracts were subjected to metabolomic analysis and functional screening. Notably, only a single growth condition induced the production of unique compounds, which were partially purified and structurally characterized by liquid chromatography high-resolution tandem mass spectrometry (LC-HRMS/MS). This strategy led to identifying a bioactive fraction containing $>30$ new glycolipids holding unusual functional groups. The active fraction showed a potent antiviral effect against enveloped viruses, such as herpes simplex virus and human coronaviruses, and high antiproliferative activity in PC3 prostate cancer cell line. The identified compounds belong to the biosurfactants class, amphiphilic molecules, which play a crucial role in the biotech and biomedical industry.
\end{abstract}

Keywords: trehalolipids; glycolipids; antiviral; antiproliferative; biosurfactant; marine bacteria; OSMAC approach; microbial natural products; mass spectrometry; metabolomics

\section{Introduction}

Natural products (NPs) of microbial origin, mainly from soil bacteria, have inspired most of our common commercial pharmaceuticals. During the last decade, a shift in focus, from the terrestrial to the marine environment, resulted in the discovery of a wide variety of new industrially relevant metabolites [1]. However, one of the main barriers is represented by the high rediscovery rate of already known metabolites, turning the drug discovery process into a waste of resources [2]. New progresses have been made to overcome these issues, prioritizing the use of talented strains. Recent advances in microbial DNA sequencing technologies allow whole genome sequencing in a rapid and cost-effective way. As a consequence, new tools for genome analysis were developed, such as antiSMASH [3,4], 
for the identification of biosynthetic gene clusters (BGCs) ranging from polyketide synthase (PKS) and non-ribosomal peptide synthetases (NRPS), to siderophores, post-translationally modified peptides (RiPPs), terpenes, and saccharides. Genome mining approach has revealed that bacterial BGCs far surpass the number of molecules isolated in lab, but often they are silent or cryptic $[5,6]$ and they are not expressed under certain conditions. The concept of "laboratory conditions" plays a fundamental role in the discovery of new NPs. Applying the right stimuli to talented microbes, overexpression of certain metabolites or induction of silent genes will be possible. Among others, the One Strain Many Compounds (OSMAC) approach has been shown to activate BGCs becoming a promising strategy for the development of new bioactive compounds and recent studies highlighted the potential of this approach applied to marine microorganisms [7]. Advancements in the untargeted metabolomics field by using tandem mass spectrometry (MS/MS) and the development of the molecular networking [8] allow a rapid comparison of a high number of metabolites expressed in different conditions. This approach could guide the selection of the unknown compounds produced and facilitate the dereplication step [6]. Selection of promising microbial candidates through genome mining, discovery of the right productive conditions and rapid analysis of metabolic products are factors potentially able to increase the success in the NPs discovery.

Following the state of the art in the discovery of NPs from marine sources, this work aimed to identify novel bioactive compounds, including biosurfactants, from the marine Rhodococcus sp. I2R, by using an OSMAC approach to unlock cryptic biosynthetic pathways, coupled with a comprehensive LC-MS/MS (liquid chromatography tandem mass spectrometry)-based untargeted metabolomic analysis and functional screening. Among the other classes of NPs, biosurfactants are well-known amphiphilic molecules, having a wide range of biotechnological applications and including glycolipids, such as the more extensively studied rhamnolipids (RLs), mannosylerythritol lipids (MELs), sophorolipids (SLs), cellobiose lipids (CL), and xylolipids (XL) $[9,10]$. Chemical industries increasingly recognize the importance of these bio-based compounds as drivers towards a bioeconomy and sustainability [11], as also indicated by the high number of patents regarding the application of biosurfactant molecules [12]. Therefore, there is an emerging interest on marine-derived glycolipids as ingredients for biomedical, biotechnological and personal care formulations [9,13-15].

Herein, we report about the fermentative production of a mixture of $>30$ novel glycolipids from Rhodococcus sp. I2R, which were identified as succinic saccharide esters, bearing an uncommon phenylacetate moiety, along with the in vitro investigation of their antiproliferative and antiviral activities.

\section{Results}

\subsection{Bacterial Isolation and Genome-Based Identification}

In the framework of marine biotechnology and bioremediation purposes, marine sediments collected during the EC18 oceanographic campaign in the Southern Tyrrhenian Sea in 2018 and stored at $-20{ }^{\circ} \mathrm{C}$ were used to isolate marine bacteria on agar plates in presence of $1 \mathrm{mM}$ of phenanthrene. Among others, a rod-shaped orange bacterium named I2R was selected for its capability to grow well on phenanthrene. The preliminary phylogenetic affiliation based on the amplification and analysis of the 16S rRNA region (see Section 4.1) was carried out and identified as Rhodococcus sp. As a result, Rhodococcus sp. CUA-806 and Rhodococcus sp. KRD197 showed the highest similarity ( $\approx 99.3 \%)$ with Rhodococcus sp. I2R. At the species level, a BLAST search against the 16S rRNA gene database, assigned a similarity of $98.59 \%$ with $R$. yunnanensis, $98.23 \%$ with $R$. cerastii, $98.01 \%$ with $R$. fascians and $R$. cercidiphylli. Due to the well-known metabolic potential of this genus, Rhodococcus sp. I2R was selected for whole genome sequencing, thereby giving 72 contigs with an overall size of $5.3 \mathrm{Mb}$ and GC content of $64 \%$ (Table 1 ). 
Table 1. General features of the genome of Rhodococcus sp. I2R.

\begin{tabular}{cc}
\hline Attribute & Value \\
\hline Genome size (bp) & $5,290,284$ \\
DNA G+C (\%) & 64.01 \\
Number of contigs & 72 \\
Longest contig length (bp) & 336,301 \\
Shortest contig length (bp) & 1117 \\
Average contig length (bp) & 73,476 \\
N50 (bp) & 195,979 \\
Number of Coding Sequences & 5210 \\
RNA genes (tRNA + rRNA) & 52 \\
\hline
\end{tabular}

The bacterial genome of our strain was compared with those from the closest phylogenetic strains Rhodococcus sp. CUA-806 (Genbank MKKD01000002.1) and KRD197 (Genbank JABFAO010000001.1) by average nucleotide identity (ANI) analysis, showing $>98 \%$ ANI values towards both strains. Therefore, these findings unveil these strains belong to the same species, as the ANI value is higher than the cut-off score (95\%) currently accepted for taxonomic inference [16].

\subsection{Genome Annotation and Biosynthetic Potential Analysis of Rhodococcus sp. I2R}

RAST [17] annotation of the bacterial genome resulted in 5219 coding sequences, of which 2325 (45\%) were included in functional categories. An overview of the subsystems for this genome is provided in Figure 1.

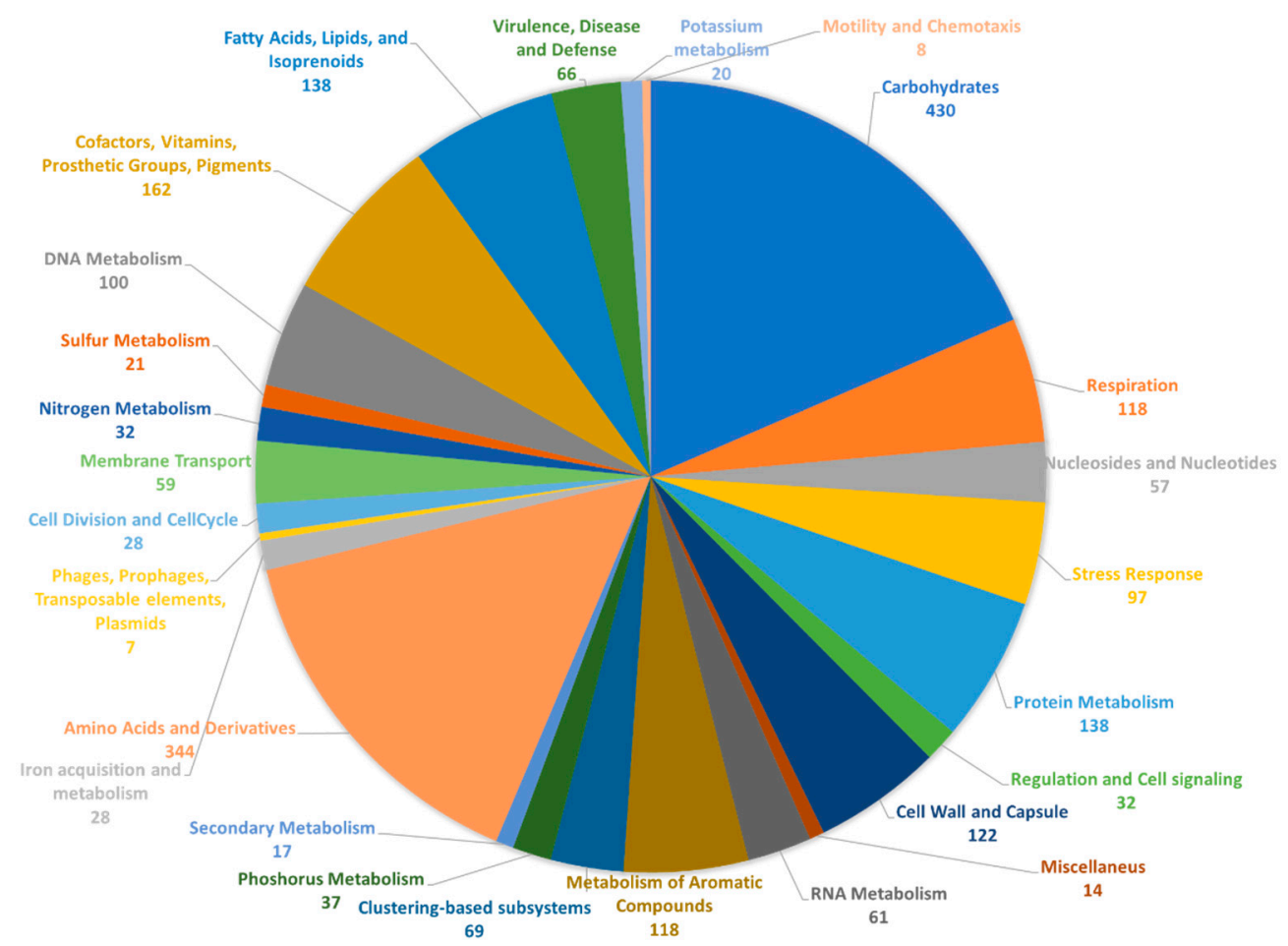

Figure 1. Overview of functional categories assigned to predicted genes from Rhodococcus sp. I2R. The whole-genome sequence of the strain I2R was annotated using RAST. The number of genes assigned to each category is indicated.

The largest functional category is represented by carbohydrates ( 430 genes), followed by amino acids and derivatives (344 genes), and cofactors, vitamins, prosthetic groups, and pigments (162 genes). Other large categories are represented by fatty acids, lipids, and isoprenoids, and protein metabolism, both with 138 genes. The genes involved in the metabolism of aromatic compounds as well as those for stress response, likely give 
Rhodococcus sp. I2R the ability to grow in polluted or harsh environments [18-20]. Indeed, this strain was isolated on phenanthrene agar plates, thus being a good candidate for bioremediation applications.

Aiming to gain a general overview of the biosynthetic potential of Rhodococcus sp. I2R, its genome was screened by antiSMASH 6.0 [4], a powerful tool to detect biosynthetic gene clusters (BGCs) involved mainly in the microbial secondary metabolism. As a result, a total of 36 putative BGCs have been identified (Table 2), including pathways encoding the biosynthesis of polyketides, ribosomal and non-ribosomal peptides, terpenes, saccharides, butyrolactones, ectoines, arylpolyenes, and fatty acids. Notably, most of these BGCs displayed partial or no similarity with any known gene clusters, suggesting the possibility of being involved in the production of novel compounds. Interestingly, more than $50 \%$ of the detected BGCs (20 out of 36) have been identified as saccharides or saccharides clustered together with NRPS, type-I and type-II PKS, terpene and fatty acid synthases, indicating that this strain is able to produce an extensive repertoire of glycosylated molecules.

Table 2. antiSMASH identification and analysis of BGCs in Rhodococcus sp. I2R whole genome sequence.

\begin{tabular}{|c|c|c|c|c|}
\hline Type & Contig & Location (nt) & Most Similar Known Cluster & Similarity $(\%)$ \\
\hline Saccharide-NRPS & 1 & $29,248-91,486$ & Coelichelin & 27 \\
\hline Saccharide & 1 & $313,381-336,301$ & Macrotetrolide & 33 \\
\hline T2PKS-saccharide & 2 & $47,197-119,676$ & Mayamycin & 63 \\
\hline Saccharide & 2 & $236,836-273,343$ & TP-1161 & 8 \\
\hline NRPS-redox-cofactor-saccharide & 3 & $1-92,466$ & - & - \\
\hline Ectoine & 4 & $116,604-127,002$ & Ectoine & 50 \\
\hline Saccharide-T1PKS & 5 & $1-59,796$ & Selvamicin & 11 \\
\hline Fatty acid & 5 & $148,163-167,687$ & - & - \\
\hline Fatty acid & 5 & $212,303-233,406$ & - & - \\
\hline Saccharide & 6 & $107,905-134,028$ & - & - \\
\hline Saccharide-terpene & 6 & $144,642-204,805$ & Isorenieratene & 42 \\
\hline Saccharide & 7 & $153-31,205$ & - & - \\
\hline Saccharide & 7 & $42,961-63,566$ & Tetronasin & 3 \\
\hline Saccharide & 7 & $96,022-137,264$ & Rimosamide & 14 \\
\hline NRPS-like & 7 & $142,446-185,022$ & - & - \\
\hline Terpene & 8 & $92,586-113,764$ & SF2575 & 6 \\
\hline Saccharide & 9 & $108,630-145,274$ & ECO-02301 & 7 \\
\hline Saccharide & 10 & $73,245-94,928$ & Streptovaricin & 4 \\
\hline Saccharide & 10 & $98,951-137,834$ & - & - \\
\hline PKS-like-amglyccycl * & 12 & $158,941-192,419$ & - & - \\
\hline Furan—fatty acid & 13 & $13,932-35,940$ & Diisonitrile antibiotic SF2768 & 11 \\
\hline NAPAA * & 15 & $1-30,389$ & - & - \\
\hline hglE-KS * & 16 & $63,473-105,151$ & Vazabitide A & 10 \\
\hline NRPS & 17 & $1-29,241$ & Atratumycin & 5 \\
\hline NRPS—saccharide & 18 & $1-79,116$ & - & - \\
\hline Butyrolactone & 21 & $68,428-79,324$ & - & - \\
\hline Arylpolyene-T1PKS—fatty acid_PKS-like & 24 & $1-67,243$ & $\begin{array}{c}\text { Abyssomicin } \\
\text { C/Atrop-Abyssomicin C }\end{array}$ & 7 \\
\hline NRPS—saccharide & 26 & $1-59,270$ & $\begin{array}{c}\text { Heterobactin A/Heterobactin } \\
\text { S2 }\end{array}$ & 63 \\
\hline NRPS & 27 & $1-54,662$ & Siamycin I & 8 \\
\hline Fatty acid-saccharide & 28 & $3562-54,528$ & Bottromycin A2 & 9 \\
\hline NRPS-like & 29 & $27,485-54,026$ & - & - \\
\hline Saccharide & 32 & $1-17,712$ & - & - \\
\hline Saccharide & 32 & $34,798-52,216$ & Tetrocarcin A & 4 \\
\hline NRPS & 39 & $1-22,870$ & - & - \\
\hline NRPS & 43 & $1-12,753$ & Atratumycin & 5 \\
\hline Saccharide & 54 & $1-5008$ & - & - \\
\hline
\end{tabular}

* Abbreviations: amglyccycl, aminoglycoside/aminocyclitol cluster; NAPAA, non-alpha poly-amino acids like e-Polylysin; hglE-KS, heterocyst glycolipid synthase-like PKS. 
The relatively high number of BGCs detected by the antiSMASH analysis of Rhodococcus sp. I2R and variability of genes highlighted by genome annotation confirmed the biotechnological interest around this genus and, for this reason, the strain I2R was selected for further studies aimed at the production of novel bioactive metabolites with pharmaceutical and biotechnological applications.

\subsection{OSMAC-Based Cultivation and Bioactivity Profiling}

Twenty-two different growth media were used to cultivate the strain I2R in small-scale cultures $(20 \mathrm{~mL})$ following an OSMAC approach in order to elicit the expression of BGCs identified by genome analysis and/or unknown pathways. The growth media selection was guided by a literature survey focused on the cultivation conditions of other reported Rhodococcus spp., and more in general, actinobacteria, leading to the production of bioactive metabolites [21-24]. Culture media were designed to explore the effects of different carbon and nitrogen sources and their concentrations on secondary metabolite biosynthesis, under high and low nutrient conditions. After 6 days of incubation at $20^{\circ} \mathrm{C}$ (late stationary phase), Rhodococcus sp. I2R was able to grow in all tested media with visible variations in pigmentation. Cultures were treated to obtain crude extracts from the exhausted broths. The yield of extracts ranged from $1 \mathrm{mg}$ to a maximum of $5 \mathrm{mg}$. The generated extracts were subjected to functional screening, including antiviral, anticancer, and biosurfactant assays. Screening results are described below.

\subsubsection{Antiviral Activity}

The twenty-two extracts obtained from the OSMAC were tested for the antiviral activity. The Vero cells were treated with the extracts at different concentrations $(125,250$, and $500 \mu \mathrm{g} / \mathrm{mL}$ ) and simultaneously infected with herpes simplex virus 1 (HSV-1). The percentage of inhibition was calculated by comparing the antiviral effect of the tested extracts with the untreated virus. Out of 22 samples tested, only 3 (SV2 SW, MSM Glu Arg, MSM Gly Arg) showed promising activity against HSV-1, with $80 \%$ and $40 \%$ inhibition at concentration of 500 and $250 \mu \mathrm{g} / \mathrm{mL}$, respectively (Figure 2). 


\section{Co-treatment Herpes simplex virus (HSV-1)}

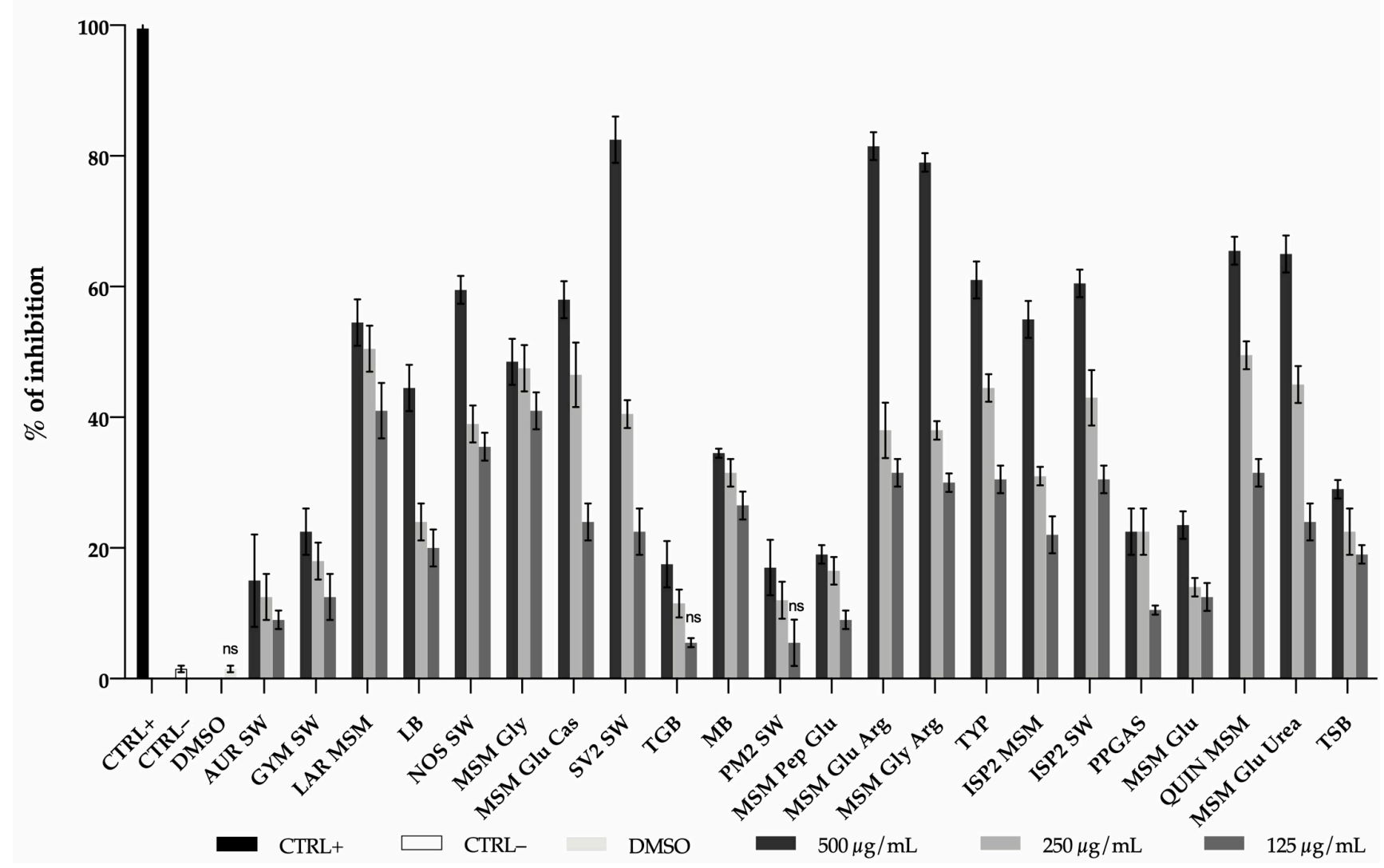

Figure 2. Evaluation of the antiviral activity of 22 crude extracts derived from Rhodococcus sp. I2R towards herpes simplex virus type 1 (HSV-1). The percentage of inhibition was calculated by counting the number of plaques obtained in the presence of extract compared to the untreated virus (CTRL-). The Greco extract [25] at $50 \mu \mathrm{g} / \mathrm{mL}$ was used as a positive control (CTRL+). Data are means of three independent experiments. Statistical significances are referred to the negative control (CTRL-). Differences between groups were determined by analysis of variance (ANOVA) and Dunnett's test was used for multiple comparisons with the control. Statistically not significant values are indicated with "ns", otherwise $p<0.005$.

\subsubsection{Anticancer Activity}

The 22 total extracts of Rhodococcus sp. I2R were assessed for potential antiproliferative effects on PC3 human prostatic carcinoma cell line and its normal counterpart PNT2 (normal prostatic epithelial cells), by using the MTT assay. PC3 and PNT2 cells were incubated with different doses of crude extracts $(1-10-100 \mu \mathrm{g} / \mathrm{mL})$, however only the highest concentration showed moderate or strong antiproliferative effect (Figure 3 and Figure S1). All the extracts inhibited PC 3 cancer cell growth after $48 \mathrm{~h}$, with cell viability ranging from 10 to $69 \%$. In particular, PC3 viability was negatively and significantly affected after exposure to the following samples: SV2 SW (25\%), PM2 SW (13\%), MSM Pep Glu $(10 \%)$. Among these three samples, SV2 SW was shown to exert the most selective antiproliferative activity, as unveiling lower cytotoxicity (2.4 times less) towards PNT2 cells (60\% of viable cells) (Figure 3 and Figure S2). 


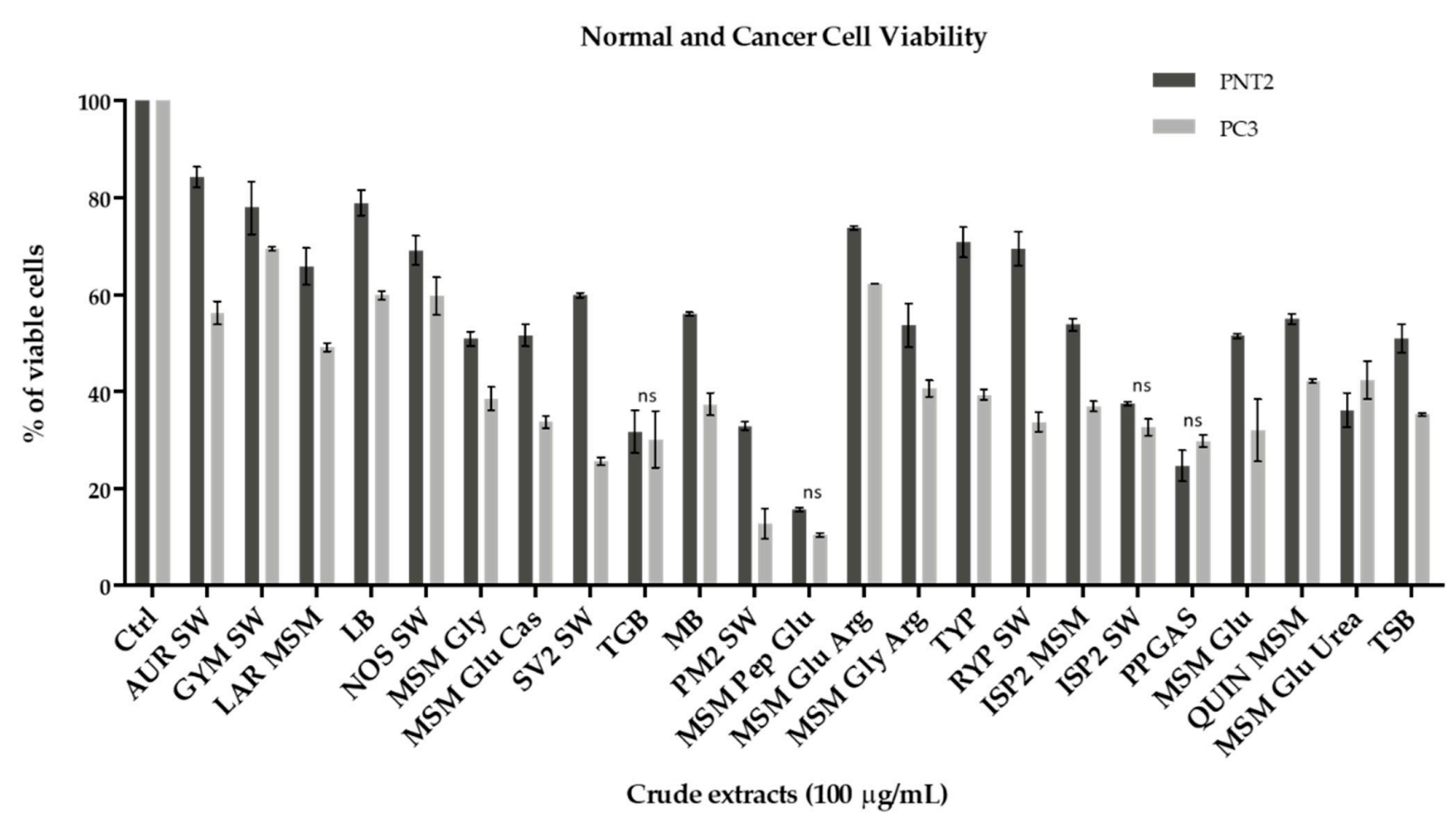

Figure 3. MTT cell viability assay on PNT2 and PC3 cell lines. Histograms represent the percentages of viable cells after $48 \mathrm{~h}$ of treatment with $100 \mu \mathrm{g} / \mathrm{mL}$ of crude extracts; assays were performed in triplicate. Cells treated with DMSO vehicle were used as control and correspond to $100 \%$ of cell viability. Statistical significances are referred to normal and cancer lines within the same group. Differences between groups were determined by analysis of variance (ANOVA) and Bonferroni test was used as post hoc test. Statistically not significant values are indicated with "ns", otherwise $p<0.005$.

\subsubsection{Biosurfactant Activity}

The obtained crude extracts were screened for biosurfactant activity using the CTAB (cetyltrimethylammonium bromide) agar method [26] to detect the production of anionic biosurfactants. The presence of such molecules is easily detected by the formation of dark blue halos. Among extracts showing a potential biosurfactant activity (Figure 4), the sample SV2 SW displayed the highest effect, which resulted to be comparable to that of $0.1 \%$ SDS and higher than that of $0.01 \%$ SDS positive controls. DMSO vehicle was used as negative control.

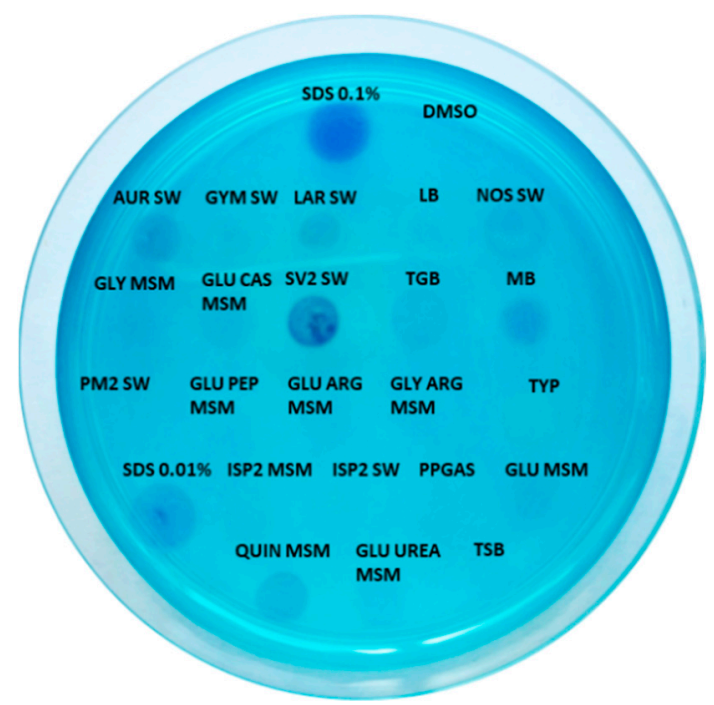

Figure 4. Biosurfactant activity of all extracts $(25 \mathrm{mg} / \mathrm{mL})$ on a CTAB agar plate. Blue halos indicate positivity to the test. SDS $0.1 \%$ and $0.01 \%$ are positive controls, while DMSO vehicle was used as negative control. 


\subsection{Molecular Networking Analysis of Rhodococcus sp. I2R Metabolism under Different Culture Conditions}

In order to highlight differences in the Rhodococcus sp. I2R metabolism caused by different nutrient regimes, the 22 extracts were subjected to low-resolution LC-MS/MS analysis in the negative ion detection mode (Figure S3). Raw MS data were preprocessed by MZmine [27] and submitted to the online platform GNPS [8] to create a molecular network (MN) by using the Feature-based Networking tool (FBMN) [28]. As a result, a wide distribution of related nodes has been detected and the MN derived from the SV2 SW condition revealed the presence of two molecular clusters showing unique nodes (Figure 5), which have been proved later to be glycolipids, and therefore biosurfactant molecules, by liquid chromatography high-resolution tandem mass spectrometry (LC-HRMS/MS) (see Section 2.7). Notably, the SV2 SW organic extract was also shown to exhibit the most interesting bioactivity profile during functional screening (see Section 2.3).

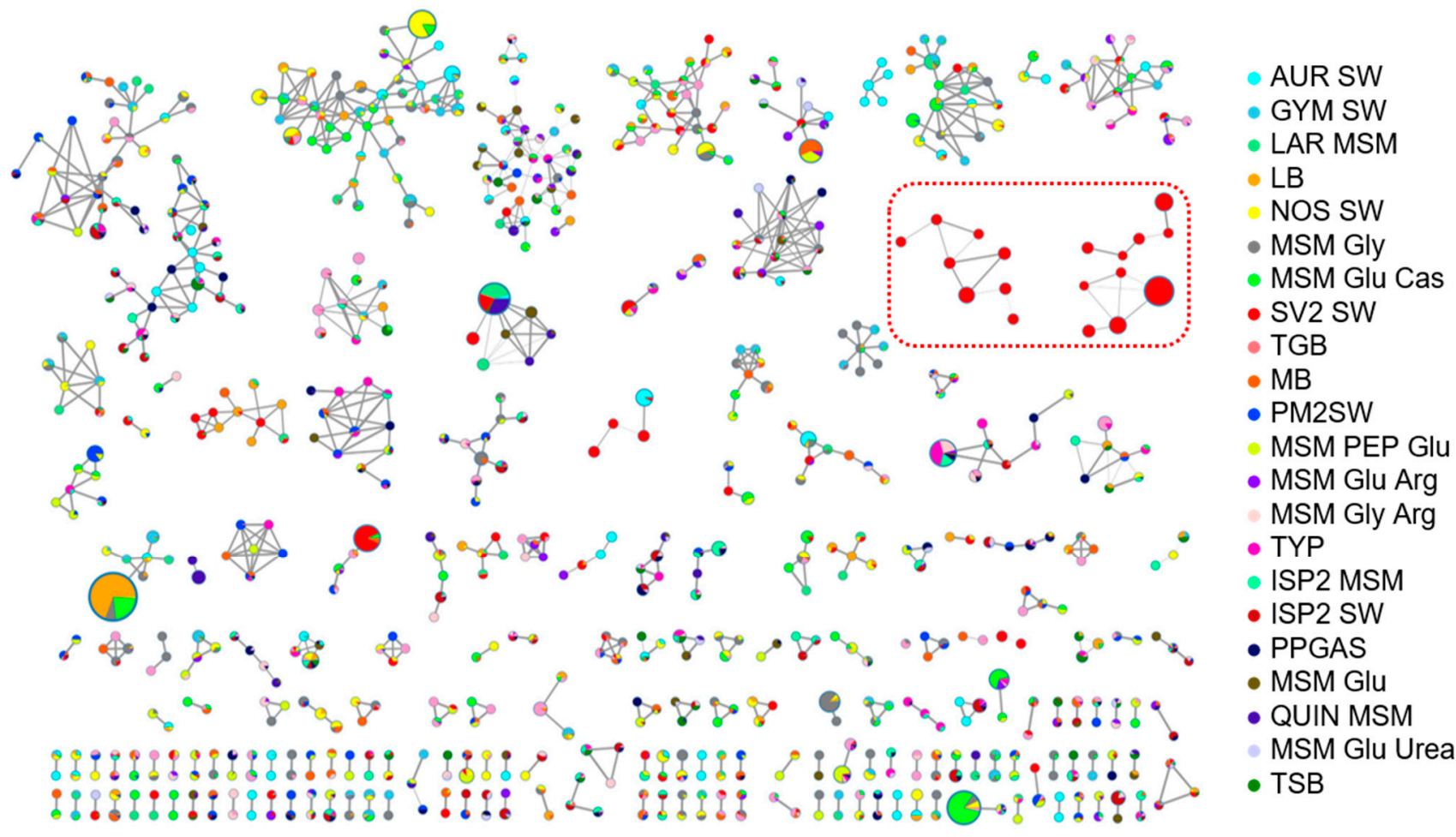

Figure 5. Molecular networking overview of crude extracts produced by Rhodococcus sp. I2R in 22 different culture media. Biosynthesis of two molecular clusters (circled in red) was triggered exclusively in the SV2 SW medium. Each color corresponds to a specific growth condition. Node size is relative to the areas of the relevant peaks in the extracted-ion chromatograms from the LC-MS run and edge thickness is relative to the cosine score similarity.

\subsection{Bioassay-Guided Fractionation of the SV2 SW Crude Extract}

Based on the metabolomic and functional screening results, sample SV2 SW was further investigated to identify the active compounds. Rhodococcus sp. I2R was scaled-up and cultivated in $400 \mathrm{~mL}$ of SV2 SW medium for 6 days, centrifuged and the supernatant extracted by EtOAc. The crude extract $(45 \mathrm{mg}$ ) was fractionated over a C18 SPE cartridge by using an $\mathrm{H}_{2} \mathrm{O} / \mathrm{MeOH}$ gradient to yield four fractions $\left(100 \% \mathrm{H}_{2} \mathrm{O}, 50 \% \mathrm{MeOH}, 90 \% \mathrm{MeOH}\right.$, $100 \% \mathrm{MeOH})$. Each eluted fraction, excluding water, was dried and weighted obtaining $6.3 \mathrm{mg}$ of $50 \% \mathrm{MeOH}, 6 \mathrm{mg}$ of $90 \% \mathrm{MeOH}$ and finally $2 \mathrm{mg}$ of $100 \% \mathrm{MeOH}$ fraction. Again, the samples were subjected to low-resolution LC-MS/MS and functional screening (using DMSO as vehicle) in order to identify the active fraction and further characterize the metabolites. 


\subsubsection{Antiviral Activity Validation}

The observed antiviral activity was particularly relevant, as shown by Figure 6 . Indeed, in co-treatment experiments where Vero cells were simultaneously infected with HSV-1 and exposed to increasing doses of SV2 SW fractions, the $90 \% \mathrm{MeOH}$ fraction (F90) unveiled a potent antiviral effect, showing $100 \%$ inhibition at 500 and $250 \mu \mathrm{g} / \mathrm{mL}$ concentrations and about $40 \%$ inhibition at a concentration of $125 \mu \mathrm{g} / \mathrm{mL}$. The $100 \% \mathrm{MeOH}$ fraction (F100) also showed a moderate percentage of inhibition of $80,60,40 \%$ at concentrations of 500,250 and $125 \mu \mathrm{g} / \mathrm{mL}$ respectively. Fraction $50 \% \mathrm{MeOH}$ (F50) did not elicit significant effect. These results clearly indicate that the F90 antiviral activity is always higher than that exerted by the crude extract (and the other fractions), thus suggesting this fraction to be enriched of antiviral compounds (Figure 6).

\section{Co-treatment (HSV-1)}

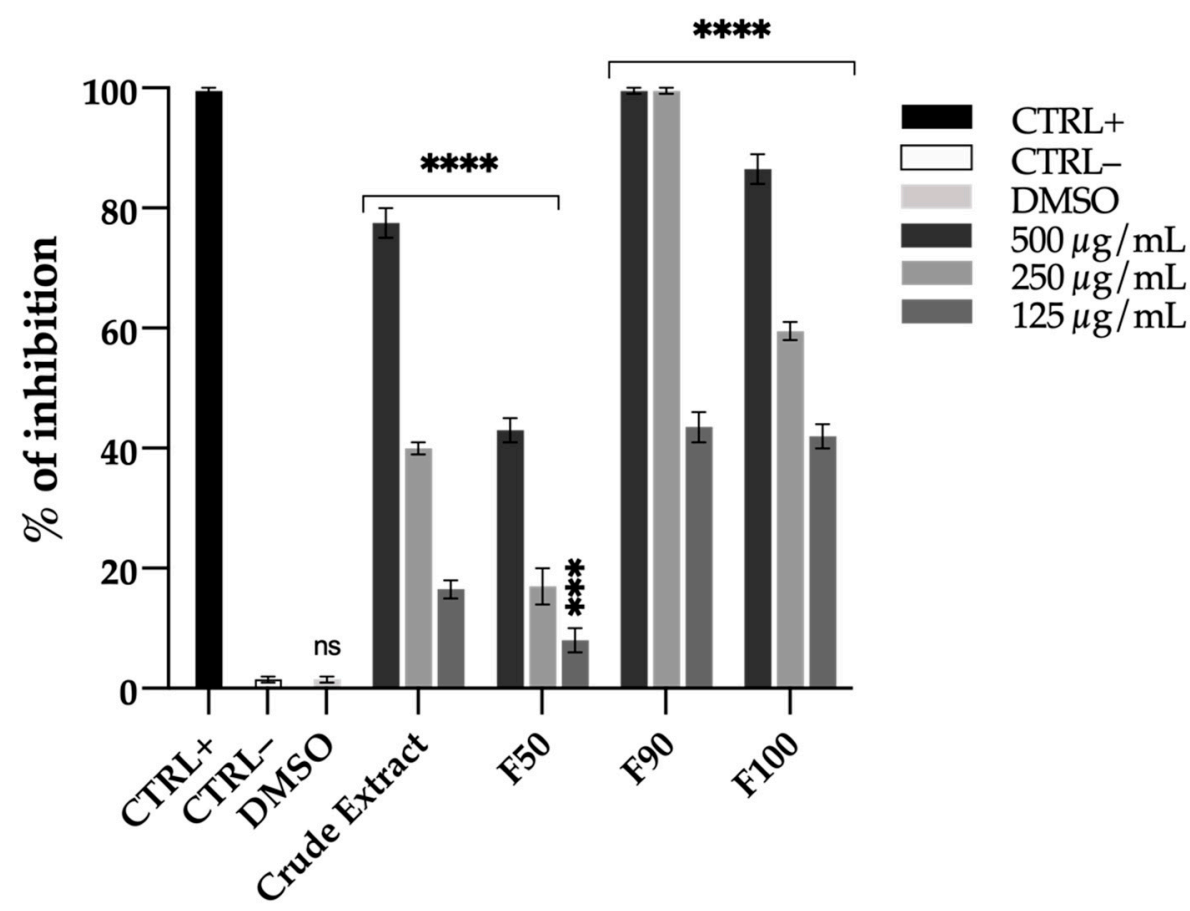

Figure 6. Antiviral effects of SV2 SW fractions against herpes simplex virus 1 (HSV-1) in co-treatment experiments. Vero cells were simultaneously infected with HSV-1 and treated with DMSO vehicle and different concentrations $(125,250$, and $500 \mu \mathrm{g} / \mathrm{mL})$ of the SV2 SW crude extract and fractions F50, F90, and F100. The negative control is represented by untreated cells. The Greco extract at $50 \mu \mathrm{g} / \mathrm{mL}$ was used as positive control (CTRL+). Data are means of three independent experiments. Statistical significances are referred to the negative control (untreated cells). Differences between groups were determined by analysis of variance (ANOVA) and Dunnett's test was used for multiple comparisons with the control. ${ }^{* * *} p<0.0002,{ }^{* * * *} p<0.0001$, ns (not significant).

In the light of these findings, we next pre-treated HSV-1 with the most active fraction F90 and evaluated its infectivity in Vero cells by plaque assay in order to assess whether the loss of viral titer could be ascribed to inhibition of viral replication and/or virus inactivation mechanisms.

For this purpose, the virus was incubated with $\mathrm{F} 90$ for $1 \mathrm{~h}$ at $37^{\circ} \mathrm{C}$, then the mixture was titrated on monolayer cells. As reported in Figure 7a, preincubation of HSV-1 with F90 completely abolished viral infectivity up to $7.8 \mu \mathrm{g} / \mathrm{mL}$ concentration. However, a significant reduction of infectious virions could be observed even at lower concentrations, thus detecting $80 \%$ viral inhibition at $3.9 \mu \mathrm{g} / \mathrm{mL}$ and $70 \%$ at $1.8 \mu \mathrm{g} / \mathrm{mL}$. Taking into account the high surfactant activity shown by F90 in CTAB assay (Figure $8 \mathrm{~b}$ ), these findings suggest 
that the antiviral action is likely due to a physicochemical interaction of biosurfactant compounds with the virus lipid membrane leading to envelope damage.

(a)

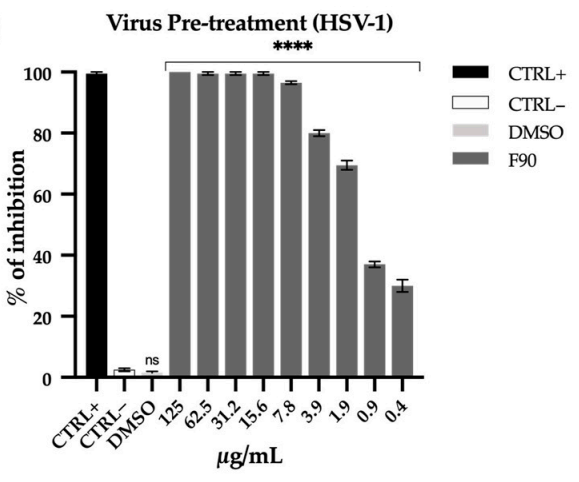

(c)
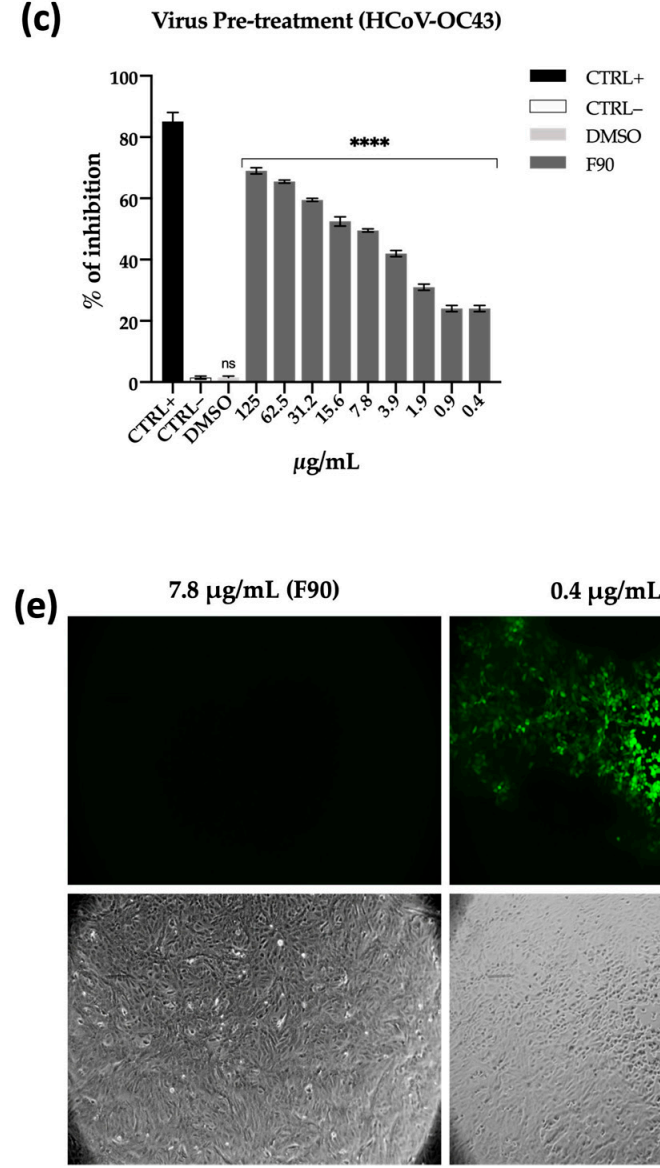

(b)

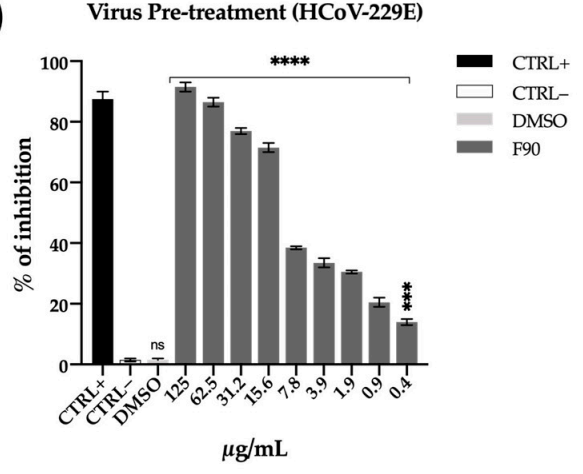

(d)

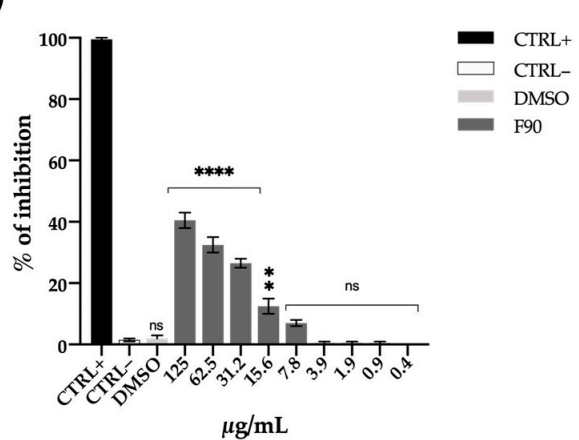

Figure 7. Antiviral activity of fraction $90 \% \mathrm{MeOH}$ (F90). The antiviral activity of $\mathrm{F} 90$ was evaluated against three enveloped viruses: herpes simplex virus type 1 (HSV-1) (a), human coronavirus 229E (HCoV-229E) (b), human coronavirus OC43 (HCoV-OC43) (c), and the envelope-free Poliovirus PV-1 (d). F90 was tested, ranging from 125 to $0.4 \mu \mathrm{g} / \mathrm{mL}$. (e) Green Fluorescent Protein herpes simplex virus type 1 (GFP HSV-1) was used to confirm the antiviral activity of $\mathrm{F} 90 \mathrm{at} 7.8 \mathrm{\mu g} / \mathrm{mL}$ (absence of fluorescence as CTRL+), while around $30 \%$ of inhibition is displayed at $0.4 \mu \mathrm{g} / \mathrm{mL}$ (presence of fluorescence). Greco extract and Pleconaril were used as positive controls (CTRL+). Untreated cells were used as negative control (CTRL-). DMSO was used as an internal negative control. Data are means of three independent experiments. Statistical significances are referred to the negative control. Differences between groups were determined by analysis of variance (ANOVA) and Dunnett's test was used for multiple comparisons with the control. ${ }^{* *} p<0.0021$; ${ }^{* * *} p<0.0002,{ }^{* * * *} p<0.0001$, ns (not significant). 
Aiming to understand if the F90 fraction was active against HSV-1 in a selective manner, we tested its activity against a broader panel of viruses, including the enveloped human coronaviruses 229E (HCoV-229E) and OC43 (HCoV-OC43), the latter belonging to the genus $\beta$-coronavirus and closely related to SARS-CoV-2, and the naked (envelope-free) Poliovirus PV-1 (all viruses used are summarized in Section 4.5.1). In the same way as above, a viral suspension of $\mathrm{HCoV}-229 \mathrm{E}$ and Poliovirus PV-1 was preincubated at $37{ }^{\circ} \mathrm{C}$ for $1 \mathrm{~h}$ with F90 and then the mixture was used to infect cells. After 24 and $48 \mathrm{~h}$ infection for $\mathrm{HCoV}-229 \mathrm{E}$ and sb1, respectively, the plates were washed and the number of plaques counted. On the other hand, to assess in vitro susceptibility of HCoV-OC43 to the F90 fraction, a viral cytopathic effect inhibition assay was performed and cell viability was monitored through the MTT assay.

Our results demonstrated that also in the case of $\mathrm{HCoV}-229 \mathrm{E}$ the antiviral activity was very high (Figure 7b), with a percentage of inhibition of 95 and $90 \%$ at 125 and $62.5 \mu \mathrm{g} / \mathrm{mL}$. At lower concentrations $(31.2$ and $15.6 \mu \mathrm{g} / \mathrm{mL}$ ) the reported activity was 75 and $70 \%$, reaching $20 \%$ of inhibition at $0.4 \mu \mathrm{g} / \mathrm{mL}$. Positive inhibition effect was also detected against the $\beta$-coronavirus HCoV-OC43 (Figure $7 \mathrm{c}$ ), showing more than $60 \%$ inhibition at concentration between 125 and $31.2 \mu \mathrm{g} / \mathrm{mL}$, gradually decreasing the effect at lower concentrations. As expected for membrane-active biosurfactants, the antiviral effect against the envelope-free Poliovirus PV-1 was considerably reduced, showing $40 \%$ and $30 \%$ of inhibition at the highest concentrations (Figure $7 \mathrm{~d}$ ). These observations provided further evidence that F90 can inhibit viral infectivity by disrupting membrane integrity or interfering with membrane components.

The antiviral effect of F90 was confirmed by fluorescent microscopy analysis using a Green Fluorescent Protein-modified herpes virus. As clearly showed by Figure 7e, at a concentration of $7.8 \mu \mathrm{g} / \mathrm{mL}$ the active fraction completely inhibited virus entry into cells and this is reflected by the absence of luminescence. On the contrary, lowering the sample concentration $(0.4 \mu \mathrm{g} / \mathrm{mL})$ the virus was able to partially infect the cells as revealed by the detected fluorescence. Inhibition of the cytopathic effect induced by the virus following treatment with the F90 has been evaluated through the MTT assay and did not show a relevant effect (Figure S4).

Taken together, these results demonstrated that the antiviral action of the $90 \% \mathrm{MeOH}$ fraction was directed to the viral particles presumably through a detergent-like mechanism.

\subsubsection{Antiproliferative and Biosurfactant Activity Validation}

The SV2 SW fractions were tested to validate the antiproliferative and biosurfactant activity (Figure 8). The results demonstrated that F90 and F100 fractions exerted a strong antiproliferative effect as reducing PC3 cell viability below 30\% at $100 \mu \mathrm{g} / \mathrm{mL}$. PNT2 cells showed higher cell viability after exposure to the same treatments (55 and $72 \%$ after incubation with F90 and F100, respectively). Interestingly, lower SV2 SW concentrations (1 and $10 \mu \mathrm{g} / \mathrm{mL}$ ) exhibited selective antiproliferative effects in PC3 cancer cells (Figures S5 and S6). Similarly, a biosurfactant effect was elicited by the same fractions using the CTAB agar assay. 


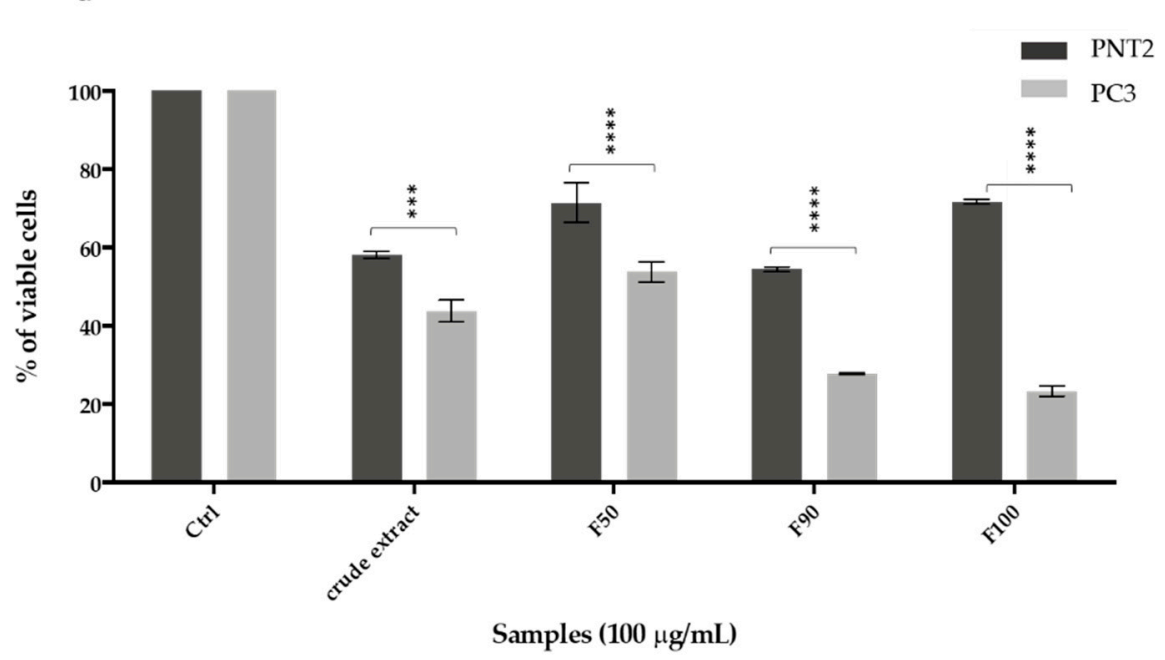

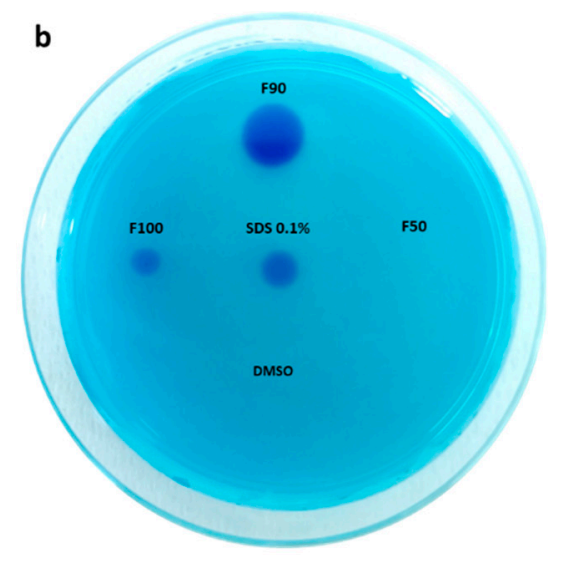

Figure 8. (a) MTT cell viability assay on PNT2 and PC3 cell lines. Histograms represent the percentages of viable cells after $48 \mathrm{~h}$ of treatment with $100 \mu \mathrm{g} / \mathrm{mL}$ of SV2 SW extract and fractions F50, F90, and F100. Data are means of three independent experiments. Statistical significances are referred to normal and cancer lines within the same group. Differences between groups were determined by analysis of variance (ANOVA) and Bonferroni test was used as post hoc test. ${ }^{* * *} p<0.0002$, ${ }_{* * * *} p<0.0001$ (b) CTAB agar assay of SV2 SW fractions assessed at $25 \mathrm{mg} / \mathrm{mL}$. SDS at the indicated concentrations $(0.1 \%$ and $0.01 \%$ ) was used as positive control, whereas DMSO vehicle as negative control.

\subsection{Structure Prediction of Novel Succinic Saccharide Esters}

For structural prediction of congeners included in the two unique biosurfactant clusters detected by MN (Figure 5), fraction F90 was subjected to LC-HRMS/MS on an LTQ Orbitrap instrument. Particularly, a survey full MS scan (performed both in positive and negative ion detection modes) unveiled a complex mixture of closely related compounds, including several series of molecules differing in degree of unsaturation and oxidation and / or by methylene units. Most intense ions (Table 3) were selected for fragmentation for structural prediction in the negative ion detection mode. The high-resolution ESI-MS of deprotonated $[\mathrm{M}-\mathrm{H}]^{-}$and protonated $[\mathrm{M}+\mathrm{H}]^{+}$molecular ions were in accordance with molecular formulas reported in Table 3 and Table S1 (mass accuracy $\leq 5 \mathrm{ppm}$ and $\leq 1 \mathrm{ppm}$ in negative and positive ion detection modes, respectively). An in-depth analysis of the HRMS/MS fragmentation patterns of the selected molecular ions suggested the F90 to be mainly composed of di- and tri-saccharide succinic esters, as sharing almost the same fragmentation pathways with succinoyl trehalolipids from an unclassified Rhodococcus (annotated as "isolate Q") [29] and the deep-sea Rhodococcus sp. BS-15 [30]. Based upon these observations, we hypothesized our compounds to be succinoyl trehalolipids, considering that (a) Rhodococcus species are widely reported to produce this class of biosurfactants [31] and (b) our isolate possesses the biosynthetic machinery for trehalose (see Section 2.7). The structure of the glucotriose lipid biosurfactant determined by Konishi et al. [30] was used as a model to tentatively assign positions of substituents linked directly to the saccharide backbone of glycolipids discussed in this study (Figure 9). 
(A)

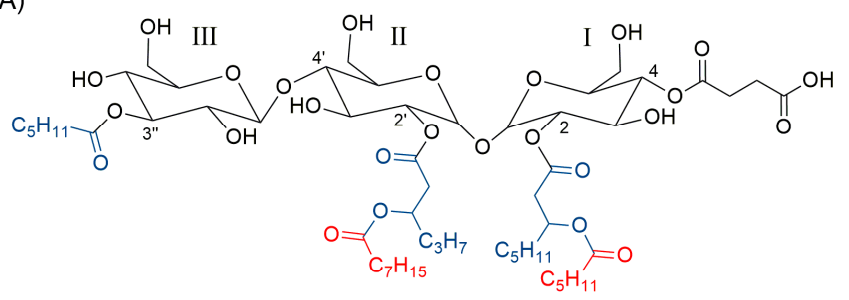

(C)

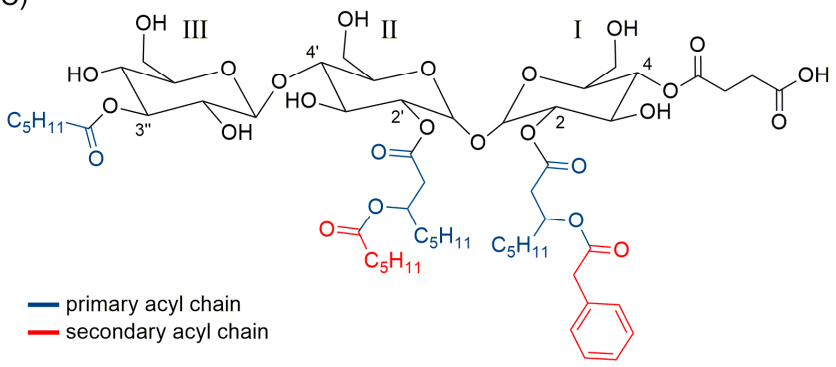

(B)

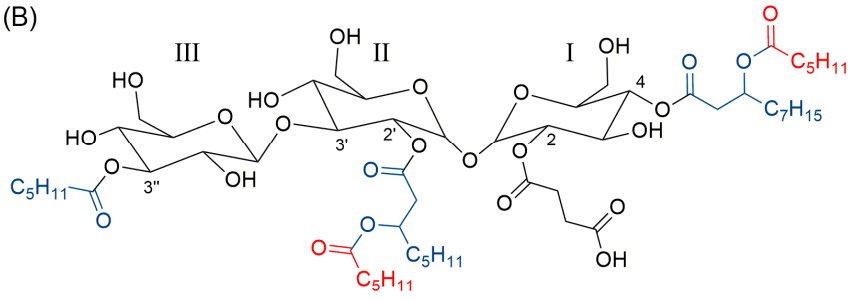

(D)

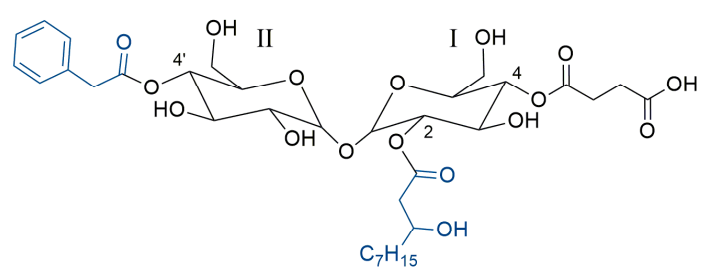

Figure 9. Succinoyl saccharide esters from Rhodococcus species. (A,B) Chemical structures of the succinoyl trisaccharide tetraesters isolated from the deep-sea Rhodococcus sp. BS-15 (A) and an unclassified Rhodococcus species, annotated as 'isolate Q' (B). These biosurfactants have a hydrophilic backbone consisting of two $\alpha, \alpha-1,1$ glycosidic linked glucose units, i.e., trehalose, which bears a third $\beta$-glucose unit (III) with a hexanoate at C3". The trehalose moiety is acylated at $\mathrm{C} 2 / \mathrm{C2}^{\prime}$ and $\mathrm{C} 4 / \mathrm{C}^{\prime}{ }^{\prime}$ with succinate and $\mathrm{O}$-ester-linked acyloxyacyl motifs. (C,D) Putative structures of a representative succinoyl trisaccharide tetraester (C) and a succinoyl disaccharide triester (D) from Rhodococcus sp. I2R discussed in this study. Positions of substituents linked to the saccharide backbone have been assigned according to compound A.

MS/MS spectra of putative succinoyl trehalolipids unveiled the presence of the fragment ion at $m / z 341.1084\left(\mathrm{C}_{12} \mathrm{H}_{21} \mathrm{O}_{11}{ }^{-}\right)$, together with ions deriving from neutral losses of one and two water molecules at $m / z 323.0978$ and 305.0873, respectively, which were consistent with a disaccharide unit consisting of two hexose rings (presumably a trehalose unit). Similarly, compounds displaying fragments at $m / z 503.1612\left(\mathrm{C}_{18} \mathrm{H}_{31} \mathrm{O}_{16}{ }^{-}\right), 485.1506$ $\left(-\mathrm{H}_{2} \mathrm{O}\right)$, and $467.1401\left(-2 \mathrm{H}_{2} \mathrm{O}\right)$ were predicted to bear a trisaccharide unit made up of three hexose moieties (most probably trehalose linked to a third glucose unit). Moreover, in all reported compounds, the saccharide backbone contained an ester-linked succinate, as shown by fragmentation reactions resulting in losses of succinic anhydride $\left(\mathrm{C}_{4} \mathrm{H}_{4} \mathrm{O}_{3}\right.$, $100.0160 \mathrm{amu})$ and/or succinic acid $\left(\mathrm{C}_{4} \mathrm{H}_{6} \mathrm{O}_{4}, 118.0266 \mathrm{amu}\right.$ ) (Figure 10, fragmentations $a$ and $a+b)$.

A careful examination of the MS tandem spectra allowed to establish the acylation patterns of the di- and tri-saccharide succinic esters as described in detail in Table 3, as ESI fragmentation mostly generated ions as a result of side-chain losses rather than by cleavage of the carbohydrate skeleton. Succinoyl glycolipids were grouped in di-, tri-, and tetraesters according to the number of primary acyl chains, i.e., acyl groups directly linked to the sugar moiety (Figure 9). Most of the detected di- and tri-saccharide succinic esters were found to be acylated with hydroxylated medium-chain fatty acids (OH-FAs), which bore either secondary acyl chains through O-ester linkage (Figure 9) or free hydroxy groups.

The presence of medium-chain OH-FAs was suggested by fragment ions deriving from the elimination of (a) the secondary acyl group (fragmentation $c$, Figure 10) or (b) a water molecule (fragmentation $b$, Figure 10), following hydrogen removal assisted by heteroatoms with lone electron pairs or negatively charged groups, acting as Lewis base [32]. Moreover, these OH-FAs were supposed to be hydroxylated at the $\beta$-position, as those bearing a free $\mathrm{OH}$ group gave diagnostic fragments generated by a typical McLafferty-type rearrangement leading to the cleavage of the $\mathrm{C} \alpha-\mathrm{C} \beta$ bond (fragmentation $e$, Figure 10) [33]. Overall, anions 10 and 11 (Figure 10) allowed us to determine the chain length of the OH-FAs directly linked to the sugar unit (fragmentation $g$ and $h$, Figure 10). 
To confirm identity of 3-OH-FAs, fatty acid methyl esters (FAMEs) were prepared from the $90 \% \mathrm{MeOH}$ fraction by methanolysis with $\mathrm{H}_{2} \mathrm{SO}_{4}$ and analyzed by GC-MS (Table 4). GC-MS analysis showed OH-FAMEs to have the base ion at $m / e=103$, characteristic for 3-hydroxylated FAMEs [34]. As molecular ions of OH-FAMEs are usually too weak to be distinguished from background noise, chain lengths were indirectly established by mass fragments at $m / e=\mathrm{M}^{+}-50$, due to the loss of water and methanol [34]. Notably, $\beta$-hydroxyoctanoate and $\beta$-hydroxydecanoate were the major compounds, as already reported by Esch et al. [29]; in addition, branched OH-FAs were also detected, even if in much lower amount as compared to their straight-chain counterparts (Table 4). Branched isomers were tentatively identified based on their retention times (and "busier" spectra) with respect to those of the analogous straight-chain esters [35]. Interestingly, an uncommon 3-OH FAME corresponding to methyl 3-OH-4-phenylbutanoate was identified using the NIST11 mass spectral library (Figure S7) [36], in full accordance with ESI MS/MS data showing succinic saccharide esters featuring this unusual acyl chain (Figure S8).

Succinic saccharide esters reported in Table 1 were found to bear hexanoate and phenylacetate units, as shown, respectively, by neutral losses of $\mathrm{C}_{6} \mathrm{H}_{12} \mathrm{O}_{2}(116.0837 \mathrm{amu})$ and $\mathrm{C}_{8} \mathrm{H}_{8} \mathrm{O}_{2}$ (136.0524 amu), from molecular and/or fragment ions. Particularly, the presence of this unusual phenylacetate unit was confirmed by GC/MS analysis of FAMEs from the $90 \% \mathrm{MeOH}$ fraction by comparing its mass spectrum with the NIST11 spectral database (Figure S7). Analysis of the ESI MS tandem spectra of the selected compounds allowed to establish unambiguously if the phenylacetate (or the hexanoate) was either directly linked to the sugar moiety, as primary acyl chain, or located at the $\beta$-hydroxy position of a certain 3-OH FA, as secondary acyl chain. Indeed, (a) the presence of fragments featuring a phenylacetate (or hexanoate) residue linked to the sugar moiety (e.g., ion 9, Figure 10; Figures S10 and S12) and (b) the observation that a McLafferty-type rearrangement (fragmentation $e$, Figure 10) occurred only in 3-OH FAs with a free OH group (Figures S8-S12), provided useful information to assemble chemical structures as reported in Table 3.

If the presence of a hexanoate unit is widely documented, it is worth mentioning that this is the first report describing succinic saccharide esters bearing a phenylacetate moiety, to best of our knowledge. Moreover, detection of glycolipids displaying a 3$\mathrm{OH}-4$-phenylbutanoate unit further supports the biosynthetic ability of Rhodococcus sp. IR2 to recruit short-chain phenylalkanoic acids to assemble these novel succinic esters. Biosynthetically, the 3-OH-4-phenylbutanoic could derive either from condensation of acetate and phenylacetate units or from oxidative degradation of phenylalkanes and/or phenyl alkanoic acids $[37,38]$ which are usually added to the bacterial growth medium. To note, the culture medium of Rhodococcus sp. IR2 was not supplemented with any phenylhydrocarbons. 
Table 3. Succinoyl saccharide esters from Rhodococcus sp. I2R.

\begin{tabular}{|c|c|c|c|c|c|c|c|}
\hline & $R_{\mathrm{t}}$ (min.) & {$[\mathbf{M}-\mathbf{H}]^{-}$} & $m / z$ & \multicolumn{2}{|c|}{$\begin{array}{c}\text { Primary } \\
\text { Acyl Chains }\end{array}$} & \multicolumn{2}{|c|}{$\begin{array}{c}\text { Secondary } \\
\text { Acyl Chains a }\end{array}$} \\
\hline & 14.6 & $\mathrm{C}_{26} \mathrm{H}_{43} \mathrm{O}_{16}$ & 611.2546 & \multicolumn{2}{|c|}{ 3-OH-C10 } & \multicolumn{2}{|c|}{-} \\
\hline & 15.4 & $\mathrm{C}_{25} \mathrm{H}_{41} \mathrm{O}_{15}$ & 581.2424 & \multicolumn{2}{|c|}{ C9 } & \multicolumn{2}{|c|}{-} \\
\hline & 16 & $\mathrm{C}_{27} \mathrm{H}_{45} \mathrm{O}_{16}$ & 625.2685 & \multicolumn{2}{|c|}{ 3-OH-C11 } & \multicolumn{2}{|c|}{ - } \\
\hline disaccharide & 16.3 & $\mathrm{C}_{26} \mathrm{H}_{41} \mathrm{O}_{15}$ & 593.2427 & \multicolumn{2}{|c|}{ C10:1 } & \multicolumn{2}{|c|}{-} \\
\hline succinic diesters & 16.7 & $\mathrm{C}_{26} \mathrm{H}_{43} \mathrm{O}_{15}$ & 595.2585 & \multicolumn{2}{|c|}{$\mathrm{C} 10$} & \multicolumn{2}{|c|}{-} \\
\hline & 18 & $\mathrm{C}_{32} \mathrm{H}_{45} \mathrm{O}_{17}$ & 701.2633 & \multicolumn{2}{|c|}{$3-\mathrm{OH}-\mathrm{C} 8^{b}$} & \multicolumn{2}{|c|}{ PhAc } \\
\hline & 19.3 & $\mathrm{C}_{30} \mathrm{H}_{51} \mathrm{O}_{16}$ & 667.3155 & \multicolumn{2}{|c|}{ 3-OH-C14 } & \multicolumn{2}{|c|}{-} \\
\hline & 19.9 & $\mathrm{C}_{34} \mathrm{H}_{49} \mathrm{O}_{17}$ & 729.2948 & \multicolumn{2}{|c|}{$3-\mathrm{OH}-\mathrm{C} 10$} & \multicolumn{2}{|c|}{ PhAc } \\
\hline \multirow{13}{*}{$\begin{array}{c}\text { disaccharide } \\
\text { succinic triesters }\end{array}$} & 16.6 & $\mathrm{C}_{34} \mathrm{H}_{49} \mathrm{O}_{18}$ & 745.2901 & 3-OH-C8 & 3-OH-PhBu & \multicolumn{2}{|c|}{-} \\
\hline & 16.9 & $\mathrm{C}_{32} \mathrm{H}_{45} \mathrm{O}_{17}$ & 701.2634 & $3-\mathrm{OH}-\mathrm{C} 8$ & PhAc & \multicolumn{2}{|c|}{-} \\
\hline & 17.5 & $\mathrm{C}_{32} \mathrm{H}_{53} \mathrm{O}_{18}$ & 725.3209 & $3-\mathrm{OH}-\mathrm{C} 8$ & $3-\mathrm{OH}-\mathrm{C} 8$ & \multicolumn{2}{|c|}{-} \\
\hline & 17.8 & $\mathrm{C}_{40} \mathrm{H}_{59} \mathrm{O}_{20}$ & 859.3571 & $3-\mathrm{OH}-\mathrm{C} 8$ & $\mathrm{diOH}-\mathrm{C} 8$ & \multicolumn{2}{|c|}{ PhAc } \\
\hline & 18.5 & $\mathrm{C}_{33} \mathrm{H}_{55} \mathrm{O}_{18}$ & 739.3367 & $3-\mathrm{OH}-\mathrm{C} 9$ & 3-OH-C8 & \multicolumn{2}{|c|}{-} \\
\hline & 19 & $\mathrm{C}_{34} \mathrm{H}_{49} \mathrm{O}_{17}$ & 729.2944 & 3-OH-C10 & PhAc & \multicolumn{2}{|c|}{-} \\
\hline & 19.4 & $\mathrm{C}_{34} \mathrm{H}_{57} \mathrm{O}_{18}$ & 753.3523 & $3-\mathrm{OH}-\mathrm{C} 10$ & $3-\mathrm{OH}-\mathrm{C} 8$ & & \\
\hline & 19.8 & $\mathrm{C}_{38} \mathrm{H}_{55} \mathrm{O}_{19}$ & 815.3307 & $3-\mathrm{OH}-\mathrm{C} 8$ & $3-\mathrm{OH}-\mathrm{C} 6$ & & ${ }_{C^{C}}$ \\
\hline & 20.8 & $\mathrm{C}_{39} \mathrm{H}_{57} \mathrm{O}_{19}$ & 829.3463 & $3-\mathrm{OH}-\mathrm{C} 8$ & 3-OH-C7 & & $\mathrm{IC}^{\mathrm{C}}$ \\
\hline & 20.9 & $\mathrm{C}_{42} \mathrm{H}_{55} \mathrm{O}_{19}$ & 863.3309 & $3-\mathrm{OH}-\mathrm{C} 8$ & 3-OH-PhBu & & \\
\hline & 21.6 & $\mathrm{C}_{40} \mathrm{H}_{59} \mathrm{O}_{19}$ & 843.3619 & $3-\mathrm{OH}-\mathrm{C} 8$ & 3-OH-C8 & & \\
\hline & 22.4 & $\mathrm{C}_{41} \mathrm{H}_{61} \mathrm{O}_{19}$ & 857.3775 & $3-\mathrm{OH}-\mathrm{C} 9$ & $3-\mathrm{OH}-\mathrm{C} 8$ & & $\mathrm{IC}^{\mathrm{C}}$ \\
\hline & 25.2 & $\mathrm{C}_{44} \mathrm{H}_{67} \mathrm{O}_{19}$ & 899.4243 & $3-\mathrm{OH}-\mathrm{C} 10$ & $3-\mathrm{OH}-\mathrm{C} 10$ & & \\
\hline $\begin{array}{c}\text { trisaccharide } \\
\text { succinic diesters }\end{array}$ & 17.2 & $\mathrm{C}_{38} \mathrm{H}_{55} \mathrm{O}_{22}$ & 863.3155 & & $\mathrm{OH}-\mathrm{C} 8$ & & \\
\hline & 18 & $\mathrm{C}_{40} \mathrm{H}_{67} \mathrm{O}_{23}$ & 915.4041 & $3-\mathrm{OH}-\mathrm{C} 10$ & $3-\mathrm{OH}-\mathrm{C} 8$ & & \\
\hline & 18.4 & $\mathrm{C}_{48} \mathrm{H}_{73} \mathrm{O}_{25}$ & 1049.4406 & $3-\mathrm{OH}-\mathrm{C} 10$ & diOH-C8 & & \\
\hline & 19.5 & $\mathrm{C}_{48} \mathrm{H}_{65} \mathrm{O}_{24}$ & 1025.3827 & $3-\mathrm{OH}-\mathrm{C} 8$ & 3-OH-PhBu & & \\
\hline & 20.1 & $\mathrm{C}_{44} \mathrm{H}_{73} \mathrm{O}_{24}$ & 985.4456 & $3-\mathrm{OH}-\mathrm{C} 8$ & 3-OH-C8 & & \\
\hline & 20.1 & $\mathrm{C}_{46} \mathrm{H}_{69} \mathrm{O}_{24}$ & 1005.4138 & $3-\mathrm{OH}-\mathrm{C} 8$ & 3-OH-C8 & & \\
\hline & 20.8 & $\mathrm{C}_{47} \mathrm{H}_{71} \mathrm{O}_{24}$ & 1019.4294 & $3-\mathrm{OH}-\mathrm{C} 9$ & $3-\mathrm{OH}-\mathrm{C} 8$ & & $\mathrm{IC}^{\mathrm{C}}$ \\
\hline & 21.5 & $\mathrm{C}_{48} \mathrm{H}_{73} \mathrm{O}_{24}$ & 1033.4447 & $3-\mathrm{OH}-\mathrm{C} 10$ & $3-\mathrm{OH}-\mathrm{C} 8$ & & $\mathrm{IC}^{\mathrm{C}}$ \\
\hline trisaccharide & 22.2 & $\mathrm{C}_{49} \mathrm{H}_{75} \mathrm{O}_{24}$ & 1047.4602 & $3-\mathrm{OH}-\mathrm{C} 10$ & 3-OH-C9 & & \\
\hline succinic triesters & 22.2 & $\mathrm{C}_{49} \mathrm{H}_{75} \mathrm{O}_{24}$ & 1047.4602 & 3-OH-C11 & $3-\mathrm{OH}-\mathrm{C} 8$ & & \\
\hline & 23.1 & $\mathrm{C}_{50} \mathrm{H}_{77} \mathrm{O}_{24}$ & 1061.4761 & $3-\mathrm{OH}-\mathrm{C} 10$ & 3-OH-C10 & & \\
\hline & 23.6 & $\mathrm{C}_{55} \mathrm{H}_{77} \mathrm{O}_{25}$ & 1137.4707 & $3-\mathrm{OH}-\mathrm{C} 9$ & $3-\mathrm{OH}-\mathrm{C} 8$ & $\mathrm{PhAc}$ & $\mathrm{PhAc}^{\mathrm{d}}$ \\
\hline & 23.7 & $\mathrm{C}_{52} \mathrm{H}_{79} \mathrm{O}_{25}$ & 1103.4865 & 3-OH-C8 & 3-OH-C8 & PhAc & $C 6^{d}$ \\
\hline & 24.6 & $\mathrm{C}_{53} \mathrm{H}_{81} \mathrm{O}_{25}$ & 1117.5018 & $3-\mathrm{OH}-\mathrm{C} 9$ & $3-\mathrm{OH}-\mathrm{C} 8$ & PhAc & $C 6^{d}$ \\
\hline & 26.3 & $\mathrm{C}_{55} \mathrm{H}_{85} \mathrm{O}_{25}$ & 1145.53296 & 3-OH-C11 & $3-\mathrm{OH}-\mathrm{C} 8$ & PhAc & $C 6^{d}$ \\
\hline & 26.3 & $\mathrm{C}_{55} \mathrm{H}_{85} \mathrm{O}_{25}$ & 1145.53296 & 3-OH-C10 & 3-OH-C9 & PhAc & $C 6^{d}$ \\
\hline trisaccharide & 27.9 & $\mathrm{C}_{54} \mathrm{H}_{83} \mathrm{O}_{24}$ & 1115.5221 & 3-OH-C8 & C10 $\quad$ C6 ${ }^{\mathrm{e}}$ & & \\
\hline succinic tetraesters & 29.4 & $\mathrm{C}_{58} \mathrm{H}_{89} \mathrm{O}_{26}$ & 1201.5579 & $3-\mathrm{OH}-\mathrm{C} 8$ & 3-OH-C8 & $\mathrm{PhAc}$ & $C 6^{d}$ \\
\hline
\end{tabular}

Abbreviations: $\mathrm{PhAc}$, phenyl acetate; 3-OH-PhBu, 3-OH-4-phenylbutanoate. ${ }^{\text {a }}$ secondary acyl chains linked to 3-OH-fatty acids as indicated in Figure 9. ${ }^{\mathrm{b}}$ 3-OH FAs with $\mathrm{OH}$ highlighted in red bear a secondary acyl chain through $O$-ester linkage. ${ }^{\mathrm{c}}$ mixture of isomers differing for the position of the secondary acyl chain which can be linked either to 1st or 2nd primary acyl chain. ${ }^{\mathrm{d}}$ compounds displaying two secondary acyl chains on the 1 st and 2 nd primary acyl chains, respectively. ${ }^{\mathrm{e}}$ compounds featuring a third sugar unit, which bears a hexanoate unit (C6). 
(1)

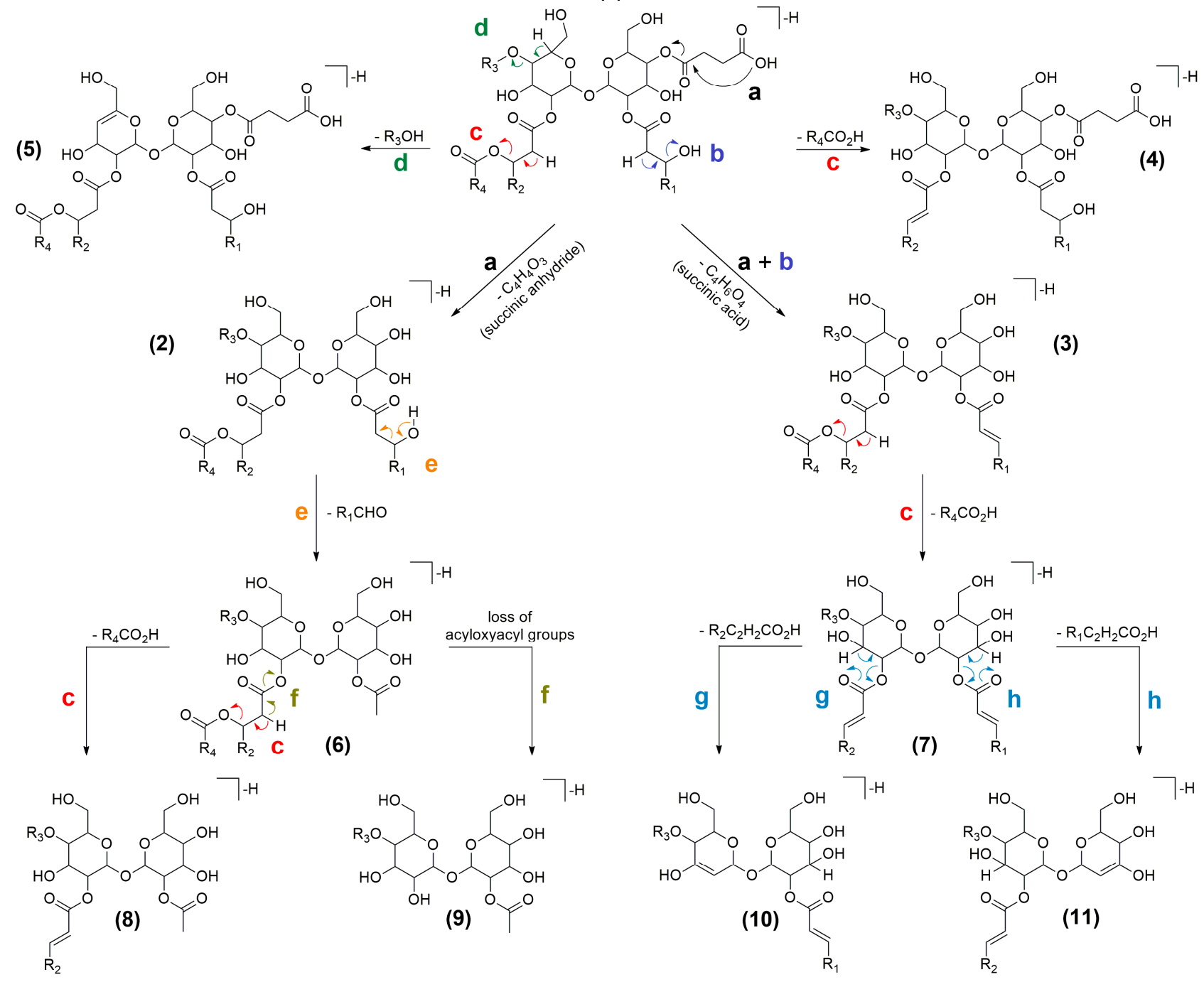

Figure 10. Proposed ESI-fragmentation pathways of succinic saccharide esters discussed in this study.

Table 4. 3-hydroxy fatty acyl composition of the $90 \% \mathrm{MeOH}$ fraction from crude extract I2R SV2 SW.

\begin{tabular}{cc}
\hline 3-Hydroxy FAMEs & Relative Abundance (\%) \\
\hline 3-OH-C6 & 0.2 \\
3-OH-C7, branched & 0.1 \\
3-OH-C7 & 0.5 \\
3-OH-C8, branched & 6.0 \\
3-OH-C8 & 31.7 \\
3-OH-C9, branched & 0.7 \\
3-OH-C9 & 8.0 \\
3-OH-C10, branched & 3.0 \\
3-OH-C10 & 36.1 \\
3-OH-4-phenylbutanoate & 2.2 \\
3-OH-C11 & 2.8 \\
3-OH-C12 & 7.6 \\
3-OH-C13 & 0.2 \\
3-OH-C14 & 1.0 \\
\hline
\end{tabular}

2.7. Identification of Putative Genes Involved in Succinic Saccharide Esters Biosynthesis

The high number of novel glycolipids expressed by Rhodococcus sp. I2R, led to the investigation of its genome through the KBase software, searching for putative genes 
involved in the production of succinic saccharide esters, integrating the experimental data provided by the chemical analysis. Bioinformatic analysis (Table 5) allowed to detect the presence of trehalose-6-phosphate synthase (ots $A$ ) and two copies of trehalose6-phosphate phosphatase (otsB) involved in de novo trehalose biosynthesis [39] and the genes malto-oligosyltrehalose synthase (treY), malto-oligosyltrehalose trehalohydrolase (treZ) and glycogen debranching enzyme (treX) involved in an alternative pathway for trehalose biosynthesis from maltooligosaccharides and starch or glycogen [40,41]. According to literature, two genes encoding fructose-bisphosphate aldolases, which catalyze the conversion of sugars from triose to hexose or vice versa, could play a key role in the succinic saccharide esters formation [42]. Furthermore, the genome annotation unveiled many glycosyltransferases and acyltransferases spread on several contigs, responsible for the biosynthesis of di/oligo/poly-saccharides and transfer of hydrophobic acyl groups to the sugar moiety, respectively. In particular, the contig 9 holds three copies of papA3 genes and one papA1, encoding putative acyltransferases, which are reported to transfer acyl groups from CoA-donor molecules to trehalose. Moreover, contig 6 hosts a putative acyltransferase sharing approximately $42 \%$ identity $\left(E\right.$ value $\left.=3 \times 10^{-168}\right)$ with the SucT acyltransferase from Mycobacterium smegmatis that adds succinyl groups to the arabinan domains of arabinogalactans and lipoarabinomannans [43]. Interestingly, this gene is adjacent to the trehalose biosynthetic genes treZ, treX, and tre $Y$ in the genome of Rhodococcus sp. I2R. Several genes putatively involved in the biosynthesis of phenylacetic acid (PhAc), a characteristic moiety of our new glycolipids, have been detected. PhAc biosynthesis is included in the phenylalanine (Phe) metabolism and could follow several biosynthetic routes (Figure 11). Two putative enzymes were found, namely (1) a catalase-peroxidase 2 (EC 1.11.1.21) forming the intermediate phenylacetamide and (2) two amidases (EC 3.5.1.4), which may lead to PhAc. However, the presence of a phenylacetaldehyde dehydrogenase, which catalyzes phenylacetaldehyde oxidation to PhAc, as well as of three copies of phenylacetate-CoA oxygenase/reductase, suggest that other undescribed genes could be involved in the PhAc production. 
Table 5. Putative genes involved in the biosynthesis of the novel succinic saccharide esters.

\begin{tabular}{|c|c|c|c|c|c|}
\hline Contig & Start & Strand & Length & Putative Gene & Function \\
\hline contig4 & 178,279 & - & 2043 & - & Trehalase \\
\hline contig6 & 117,624 & + & 2274 & treX & Glycogen debranching enzyme \\
\hline contig6 & 119,901 & + & 2418 & treY & Putative maltooligosyl trehalose synthase \\
\hline contig6 & 122,315 & + & 1740 & treZ & Malto-oligosyltrehalose trehalohydrolase \\
\hline contig15 & 69,438 & - & 2550 & ots $B$ & Trehalose-6-phosphate phosphatase \\
\hline contig18 & 99,608 & - & 2181 & tres & Trehalose synthase \\
\hline contig19 & 37,715 & + & 3192 & ots $B$ & Trehalose-6-phosphate phosphatase \\
\hline contig23 & 53,441 & + & 1458 & ots $A$ & Trehalose-6-phosphate synthase \\
\hline contig44 & 6907 & + & 1068 & $f b a A$ & Fructose-bisphosphate aldolase \\
\hline contig44 & 9581 & + & 1041 & $f b a A$ & Fructose-bisphosphate aldolase \\
\hline contig6 & 115,388 & + & 2202 & suct & Putative succinoyl transferase \\
\hline contig5 & 46,744 & - & 1887 & - & Trehalose O-mycolyltransferase \\
\hline contig9 & 137,187 & + & 1461 & papA3 & Acyltransferase papA3 \\
\hline contig9 & 138,665 & + & 1431 & papA1 & SL659 acyltransferase papA1 \\
\hline contig9 & 140,099 & + & 1404 & papA3 & Acyltransferase papA3 \\
\hline contig9 & 143,010 & + & 1488 & papA3 & Acyltransferase papA3 \\
\hline contig2 & 114,384 & + & 1071 & paaK & Phenylacetate-CoA oxygenase/reductase, PaaK subunit \\
\hline contig3 & 53,842 & + & 1044 & paaK & Phenylacetate-CoA oxygenase/reductase, PaaK subunit \\
\hline contig3 & 219,048 & + & 1449 & $f e a B$ & Phenylacetaldehyde dehydrogenase \\
\hline contig4 & 26,516 & - & 2238 & katG & Catalase-peroxidase 2 \\
\hline contig4 & 233,312 & - & 204 & paaK & Phenylacetate-CoA oxygenase/reductase, PaaK subunit \\
\hline contig14 & 61,296 & + & 795 & amiE & Aliphatic amidase AmiE \\
\hline contig20 & 84,586 & - & 840 & amiE & Aliphatic amidase AmiE \\
\hline contig7 & 14,325 & + & 3195 & $m m p L 3$ & Trehalose monomycolate exporter MmpL3 \\
\hline contig10 & 71,540 & - & 1371 & $\operatorname{lpq} Y$ & Trehalose-binding lipoprotein LpqY \\
\hline contig12 & 94,464 & + & 2226 & mmpL3 & Trehalose monomycolate exporter MmpL3 \\
\hline contig17 & 98,444 & - & 2136 & $m m p L 3$ & Trehalose monomycolate exporter MmpL3 \\
\hline contig5 & 96,103 & + & 1053 & sugC & Trehalose import ATP-binding protein SugC \\
\hline contig5 & 265,744 & + & 1050 & $\operatorname{sug} A$ & Trehalose transport system permease protein SugA \\
\hline contig5 & 266,790 & + & 822 & sugB & Trehalose transport system permease protein SugB \\
\hline contig7 & 42,107 & - & 1101 & sugC & Trehalose import ATP-binding protein SugC \\
\hline contig7 & 42,961 & - & 840 & sugB & Trehalose transport system permease protein SugB \\
\hline contig7 & 43,911 & - & 951 & $\operatorname{sug} A$ & Trehalose transport system permease protein SugA \\
\hline contig7 & 56,201 & + & 948 & $\operatorname{sug} A$ & Trehalose transport system permease protein SugA \\
\hline contig7 & 100,213 & - & 1083 & sugC & Trehalose import ATP-binding protein SugC \\
\hline contig10 & 68,393 & - & 1170 & sugC & Trehalose import ATP-binding protein SugC \\
\hline contig10 & 69,232 & - & 834 & $\operatorname{sug} B$ & Trehalose transport system permease protein SugB \\
\hline contig10 & 70,173 & - & 942 & $\operatorname{sug} A$ & Trehalose transport system permease protein SugA \\
\hline contig13 & 120,539 & - & 1077 & sugC & Trehalose import ATP-binding protein SugC \\
\hline contig20 & 57,846 & - & 1149 & sugC & Trehalose import ATP-binding protein SugC \\
\hline contig20 & 59,851 & - & 867 & sugB & Trehalose transport system permease protein SugB \\
\hline contig20 & 60,832 & - & 978 & $\operatorname{sug} A$ & Trehalose transport system permease protein SugA \\
\hline
\end{tabular}




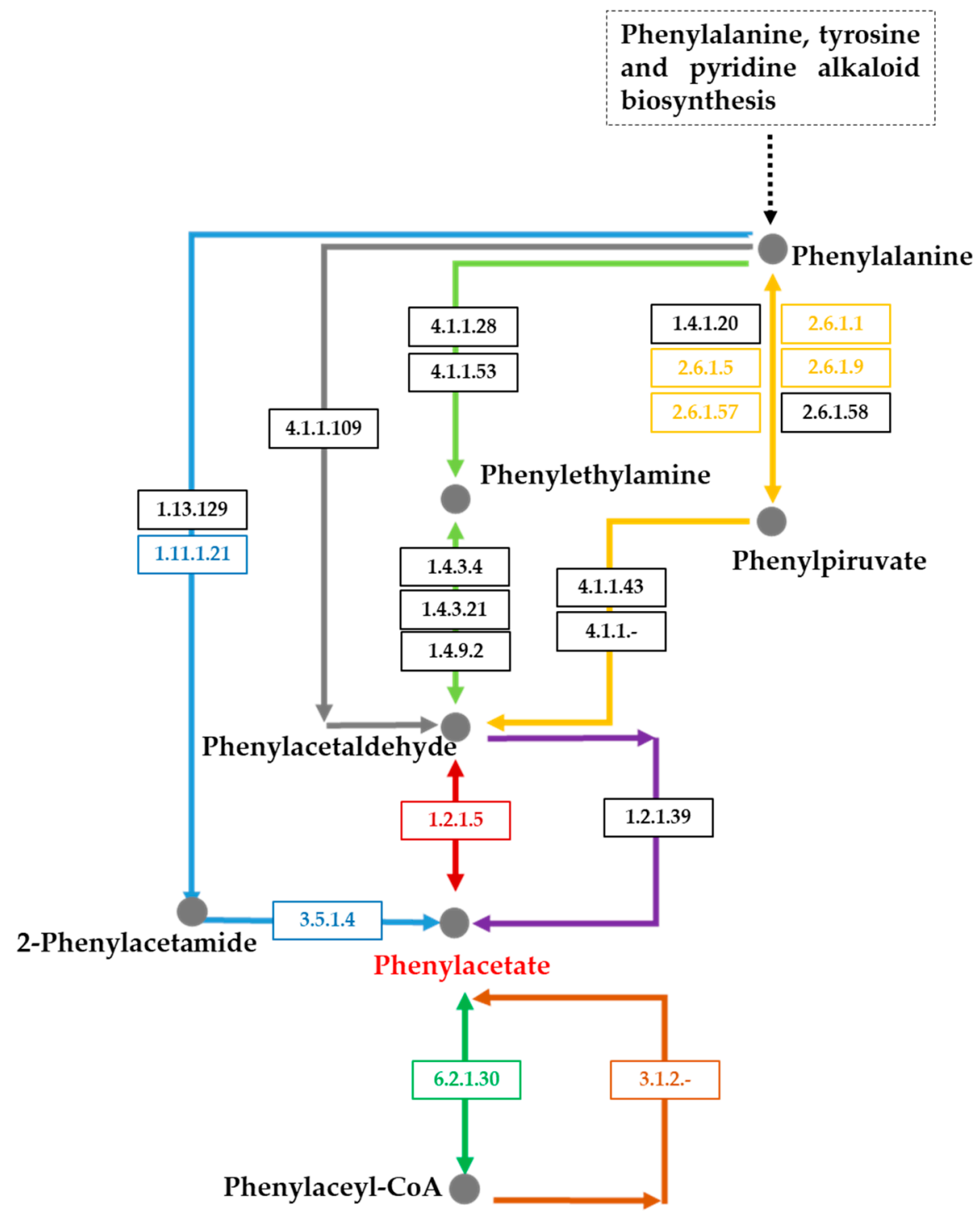

Figure 11. Phenylacetic acid (PhAc) biosynthesis from phenylalanine (Phe). In bacteria, PhAc is usually produced from Phe via the intermediate phenylpyruvate (PhePA). This route foresees transamination of Phe to PhePA (yellow arrow), which may undergo decarboxylation to phenylacetaldeide (PhAcld) and subsequent oxidation to PhAc (red arrow). Other biosynthetic ways, excluding formation of the intermediate PPA, foresee (a) decarboxylation of Phe to phenylethylamine (PheEA) (light green arrow), conversion to PhAcld and oxidation to PhAc, or (b) transformation into phenylacetamide (PhAcAM) (blue arrow), then converted to PhAc. Finally, enzymatic activation of PhAc to phenylacetyl-CoA is expected to be an important step to assemble succinic saccharide esters bearing a PhAc functional group. Colored boxes indicate enzymes involved in PhAc production that have been detected in the genome of Rhodococcus sp. I2R while dark boxes indicate enzymes that have not been identified.

\section{Discussion}

Marine Actinobacteria are considered a treasure for drug discovery and biotechnological industries, but the high rate of re-discovery of already known molecules represents an issue. In this work, to overcome this problem, an untargeted approach combining genomic, metabolomics and microbiology was applied to induce the production of novel bioactive molecules by the marine Rhodococcus sp. I2R. The taxonomic analysis demonstrated this isolate to be closely related to Rhodococcus sp. CUA-806 and KRD197, which have been previously isolated from marine [44] and polar [45] habitats, respectively, and reported to have high biosynthetic potential. Rhodococcus is a promising bacterial genus because of its 
metabolic versatility and ability to degrade a wide range of recalcitrant compounds and survive in highly polluted environments as recently highlighted by Cappelletti et al. [14]. Genome mining of Rhodococcus sp. I2R revealed the presence of 36 BGCs, around $40 \%$ of them without similarity with known genes and with a prevalence of saccharide genes (above $50 \%$ of total BGCs), indicating the production of glycosylated molecules. In the light of the biosynthetic potential of this strain, an OSMAC approach was applied to elicit the production of novel bioactive molecules. As a fact, through culture media variation (i.e., varying the concentration of carbon, nitrogen, phosphorous, inorganic salts, etc.), it is possible to upregulate or trigger the production of certain secondary metabolites produced by talented microorganisms [7,46-48]. In this study, the OSMAC strategy associated to bioassays allowed the selection of a specific growth condition expressing unique, structurally related metabolites, as highlighted by molecular networking (MN). MN resulted to be an effective strategy to assess the effects of different culture conditions on the microbial metabolism and shorten dereplication time [48].

Following these observations, chemical analysis of the enriched fraction F90 led to the identification of these metabolites as novel succinic saccharide esters, by integration of HR-MS/MS and GC-MS data. As often occurs for glycolipids [49], this complex mixture contained homologous compounds series and isomers and could not be separated into pure compounds. However, the F90 fraction was suitable for LC-MS studies and an in-depth analysis of HR-MS tandem spectra allowed to predict the acylation pattern of most abundant succinic di- and tri-saccharide esters. In addition to featuring succinate, the saccharide backbone was found to be acylated with hydroxylated medium-chain fatty acids, hexanoic acid, short chain phenylalkanoic acids (i.e., phenyl acetic and 3-OH-4-phenylbutanoic acids), and O-ester-linked acyloxyacyl motifs. As succinic saccharide esters from Rhodococcus spp. always have a trehalose unit and Rhodococcus sp. I2R possesses the biosynthetic machinery for trehalose, it could be argued these novel biosurfactants are succinoyl trehalolipids. Succinoyl trehalolipids have already been reported from other Rhodococcus, as well as the trisaccharo-lipids have been discovered both from Rhodococcus and other actinobacteria [14,29-31], nevertheless, to the best of our knowledge, this is the first report about the presence of phenylacetic acid as functional group of microbial glycolipids.

In general, biosurfactant molecules can be applied in various area such as the nutrient, cosmetic, textile, varnish, mining, oil recovery and pharmaceutical industries, as showing lower toxicity and improved physicochemical and functional properties in comparison to their synthetic analogues [50-54]. However, one of the main barriers to the biotechnological development of trehalolipids is due to the fact that they are often cell-bound, thus hampering the large-scale production and purification due to high downstream costs [13]. The ability of microbial producers to release specific glycolipids extracellularly may help to overcome this issue, thus making easier recovery of the target compounds. Examples of Rhodococcus strains as producers of an extracellular mixture of trehalolipids using glycerol or n-hexadecane as sole carbon source are reported [55]. Notably, in this work, the SV2 SW medium employed for cultivation of Rhodococcus sp. I2R stimulated the production of the glycolipid mixture in the extracellular environment, thus representing an advantage from a biotechnological perspective. SV2 SW medium (1.5\% glucose, $1.5 \%$ glycerol, $1.5 \%$ peptone, $0.1 \% \mathrm{CaCO}_{3}$ in filtered natural sea water) differentiates from the other media used in this study mainly for the relatively high concentration of nutrients, such as glycerol, glucose and peptone, which could trigger the production of the new compounds. It is widely documented that glycerol induces bacterial biosurfactants production [26,56-58], suggesting that this nutrient could play an important role in the production of succinic saccharide esters from Rhodococcus sp. I2R. However, the synergic effect of some or all of these ingredients cannot be excluded.

To date, trehalolipids have been poorly investigated as natural compounds for pharmaceutical applications [59]. Herein, we have demonstrated that the enriched fraction of succinoyl trehalolipids exerted high antiproliferative activity on a prostate cancer cell line (PC3) at $100 \mu \mathrm{g} / \mathrm{mL}$ while being significantly less cytotoxic to the normal counterpart 
(PNT2) (Figure 3). Glycolipid biosurfactants are already known to exhibit growth-inhibitory effects on many cancer cell types (e.g., SKW-3, BV-173 and HL-60) [60].

Moreover, the enriched glycolipid fraction showed a potent antiviral effect towards enveloped viruses, including herpes simplex virus type 1 and $\alpha$ - and $\beta$ - human coronaviruses, which correlates with the observed high biosurfactant activity. Therefore, viral inhibition could be due to an interaction of the biosurfactants molecules with viral lipid envelope, as demonstrated for bacterial lipopeptides able to inactivate enveloped viruses, such as retroviruses and herpes viruses, by ion channels formation [61-63]. With this regard, it is worth mentioning that a succinoyl-trehalose lipid from Rhodococcus erythropolis has been reported to inhibit herpes simplex virus and influenza virus with $\mathrm{LD}_{50}$ values of 11 and $33 \mu \mathrm{g} / \mathrm{mL}$, respectively [64], however, this antiviral activity was not clearly documented [64-66]. Moreover, it has been proven that a trehalose-6,6'-dimycolate induces resistance to influenza virus infection in mice through an augmented interferon production in T-lymphocytes $[67,68]$. Notably, to the best of our knowledge, this is the first manuscript describing the antiviral effects of succinoyl trehalolipids towards coronaviruses, including a $\beta$-coronavirus closely related to SARS-CoV-2.

Microbial expression of succinoyl trehalolipids is already known, however, the genetic basis and its regulation are still poorly understood. Although the elucidation of the biosynthetic pathway of glycolipids from Rhodococcus sp. I2R requires gene expression and functional genomics studies, a preliminary genome annotation allowed to find putative genes encoding trehalose biosynthesis [39-41] and acyltransferases catalyzing acylation of the sugar residue. To this date, only a putative acyl-CoA transferase, named trehalose lipid synthase $\mathrm{A}(t l s A)$, has been shown to play a key role in the addition of acyl groups to the trehalose moiety to assemble succinoyl trehalolipids from Rhodococcus sp. SD-74 [42]. In a Blast search, using TlsA as query sequence, four papA genes (clustered together in contig 9) from Rhodococcus sp. I2R were identified as the closest homologues, sharing approximately $30 \%$ similarity with TlsA ( $E$ values between $8 \times 10^{-70}$ and $8 \times 10^{-30}$ ). In addition, bioinformatic analysis shed light on potential biosynthetic routes leading to the formation of phenylacetic acid from phenylalanine, unveiling the ability of Rhodococcus sp. I2R to produce this unprecedented building block found in our novel succinic saccharide esters.

\section{Materials and Methods}

\subsection{Isolation, Identification, and Genome Sequencing of Strain I2R}

The strain I2R was isolated on agar plates containing Mineral Salt Medium (MSM) supplemented with $1.0 \mathrm{mM}$ of phenanthrene from marine sediments collected during the oceanographic campaign "Earth Cruisers 18" in the Southern Tyrrhenian Sea in February 2018. The phylogenetic affiliation of the bacterium was performed through the $16 \mathrm{~S}$ rRNA genes amplification and analysis. The bacterial genomic DNA was isolated using "GeneElute Bacterial genomic DNA kit" according to the manufacturer instructions (SigmaAldrich, Darmstadt, Germany) from a $2 \mathrm{~mL}$ I2R culture in TYP and used as template for the PCR.

PCR was carried out in $50 \mu \mathrm{L}$ reaction containing DreamTaq PCR Master Mix (a ready-to-use solution containing DreamTaq DNA Polymerase, optimized DreamTaq buffer, $\mathrm{MgCl}_{2}$, and dNTPs) and $0.2 \mu \mathrm{M}$ of primer Eub27 F (Forward, seq: 50-AGAGTTTGATCCTG GCTCAG-30) and Univ1492R (Reverse, seq: 50-GGTTACCTTGTTACGACTT-30) [69]. The reaction conditions used were: one cycle $\left(95^{\circ} \mathrm{C}\right.$ for $\left.2 \mathrm{~min}\right), 30$ cycles $\left(95^{\circ} \mathrm{C}\right.$ for $30 \mathrm{~s}, 55^{\circ} \mathrm{C}$ for $30 \mathrm{~s}$, and $72{ }^{\circ} \mathrm{C}$ for $1 \mathrm{~min}$ ), with a final extension of $5 \mathrm{~min}$ at $72{ }^{\circ} \mathrm{C}$. $\mathrm{PCR}$ products were then purified by GenEluteTM PCR Clean-UP kit (Sigma-Aldrich, Darmstadt, Germany), the purified PCR products were sequenced by Eurofins Genomics (Ebersberg, Germany). Both end sequences obtained by submitting the forward and the reverse to Prabi CAP3 [70] (http:/ / doua.prabi.fr/software/cap3, accessed on 1 July 2020) were submitted to BLAST for preliminary phylogenetic analysis.

A total of $1 \mu \mathrm{g}$ of genomic DNA was used for the whole genome sequencing, performed by Macrogen Europe (Amsterdam, The Netherlands) using the Illumina No- 
vaSeq 6000 platform, with a read length of $151 \mathrm{bp}$. The obtained 16,283,548 raw reads were trimmed through Trimmomatic tool (v0.36) [71] (http:/ / www.usadellab.org/cms/ index.php?page=trimmomatic, accessed on (20 August 2020) to remove adaptor and low-quality sequences, and a quality check was obtained with FastQC (v0.11.5) [72] ( https:/ /www.bioinformatics.babraham.ac.uk/projects/fastqc/, accessed on 1 September 2020.

Finally, after a K-mer analysis through Jellyfish (v2.2.10) [73] (http:/ / www.genome. umd.edu/jellyfish.html, accessed on 1 September 2020) to estimate the genome length, the de novo assembly was performed using SPAdes [74] (https:/ / cab.spbu.ru/software/ spades /, accessed on 5 September 2020) and the completeness of the genome was assessed by BUSCO (v3.0.2) analysis [75] (https:/ / busco.ezlab.org/, accessed on 5 September 2020).

Genome-based identification was carried out using ANI Calculator by EZBiocloud [76]. The sequence of Rhodococcus sp. I2R generated in this study have been deposited in the GenBank database under the accession number JAHUTG000000000 for bacterial whole genome genes.

\subsection{Genome Annotation}

The obtained genome was automatically annotated using both RASTtk (v1.073) [17] and PROKKA (v1.14.5) [77] by Kbase [78]. The metabolomic pathways were reconstructed performing KEGG BlastKOALA and KEGG mapping [79] analysis, filling the gaps manually. Finally, antiSMASH 6.0 (detection strictness: loose) [80] was applied to detect and annotate the biosynthetic gene clusters (BGCs) contained in the whole genome sequence.

\subsection{OSMAC Approach and Growth Media}

A single colony of strain I2R was used to inoculate $10 \mathrm{~mL}$ of liquid medium TYP in $50 \mathrm{~mL}$ conical tubes and incubated for $48 \mathrm{~h}$ at $20^{\circ} \mathrm{C}$ at $180 \mathrm{rpm}$. After the incubation, this pre-inoculum was centrifuged at $5000 \times g$ at $4{ }^{\circ} \mathrm{C}$ for $20^{\prime}$, the supernatant discarded and the pellet washed twice with $10 \mathrm{~mL}$ of sterile water to eliminate residues of the TYP medium and centrifuged. Finally, the pellet was resuspended with $5 \mathrm{~mL}$ of sterile water and $200 \mu \mathrm{L}$ were used to inoculate 22 flasks ( $100 \mathrm{~mL}$ volume) containing $20 \mathrm{~mL}$ of the growth media listed below. Cultures were incubated for 6 days at $20^{\circ} \mathrm{C}$ at $180 \mathrm{rpm}$. The list of growth media used for the OSMAC approach is detailed below. Filtered sea water $(\mathrm{SW})$, autoclaved distilled water and $\mathrm{MSM}\left(\mathrm{KH}_{2} \mathrm{PO}_{4} 0.7 \mathrm{~g} / \mathrm{L}, \mathrm{Na}_{2} \mathrm{HPO}_{4} 0.9 \mathrm{~g} / \mathrm{L}, \mathrm{NaNO}_{3}\right.$ $2 \mathrm{~g} / \mathrm{L}, \mathrm{MgSO}_{4} 0.4 \mathrm{~g} / \mathrm{L}, \mathrm{CaCl}_{2} 0.1 \mathrm{~g} / \mathrm{L}$ ) have been used to prepare the growth media:

AUR SW: starch $10 \mathrm{~g} / \mathrm{L}$, glucose $10 \mathrm{~g} / \mathrm{L}$, glycerol $10 \mathrm{~g} / \mathrm{L}$, peptone $5 \mathrm{~g} / \mathrm{L}$, yeast extract $2 \mathrm{~g} / \mathrm{L}$, in sea water.

GYM SW: glucose $4 \mathrm{~g} / \mathrm{L}$, yeast extract $4 \mathrm{~g} / \mathrm{L}$, malt extract $4 \mathrm{~g} / \mathrm{L}, \mathrm{CaCO}_{3} 2 \mathrm{~g} / \mathrm{L}$, in sea water.

LAR MSM: mannitol $30 \mathrm{~g} / \mathrm{L}$, glucose $10 \mathrm{~g} / \mathrm{L}$, yeast extract $5 \mathrm{~g} / \mathrm{L}$, ammonium succinate $5 \mathrm{~g} / \mathrm{L}$, in MSM.

LB: tryptone $10 \mathrm{~g} / \mathrm{L}$, yeast extract $5 \mathrm{~g} / \mathrm{L}, \mathrm{NaCl} 10 \mathrm{~g} / \mathrm{L}$, in distilled water.

NOS SW: glucose $20 \mathrm{~g} / \mathrm{L}$, yeast extract $3 \mathrm{~g} / \mathrm{L}$, peptone $10 \mathrm{~g} / \mathrm{L}$, malt extract $15 \mathrm{~g} / \mathrm{L}$, Maltose $20 \mathrm{~g} / \mathrm{L}$, in sea water.

MSM Gly: glycerol $10 \mathrm{~g} / \mathrm{L}$, in MSM.

MSM Glu Cas: glucose $10 \mathrm{~g} / \mathrm{L}$, casein hydrolyzed $15 \mathrm{~g} / \mathrm{L}$, in MSM.

SV2 SW: glucose $15 \mathrm{~g} / \mathrm{L}$, peptone $15 \mathrm{~g} / \mathrm{L}$, glycerol $15 \mathrm{~g} / \mathrm{L}, \mathrm{CaCO}_{3} 1 \mathrm{~g} / \mathrm{L}$, in sea water.

TGB: thioglycollate broth with resazurine (Condalab, Madrid, Spain) in distilled water.

MB: marine broth (Condalab, Madrid, Spain) in distilled water.

PM2 SW: starch $10 \mathrm{~g} / \mathrm{L}$, yeast extract $4 \mathrm{~g} / \mathrm{L}$, peptone $2 \mathrm{~g} / \mathrm{L}, \mathrm{Fe}_{2}\left(\mathrm{SO}_{4}\right)_{3} \times 4 \mathrm{H}_{2} \mathrm{O}$ $40 \mathrm{mg} / \mathrm{mL}$, in sea water.

MSM Pep Glu: glucose $10 \mathrm{~g} / \mathrm{L}$, peptone $10 \mathrm{~g} / \mathrm{L}$, in MSM.

MSM Glu Arg: glucose $10 \mathrm{~g} / \mathrm{L}$, arginine $30 \mathrm{mM}$, in MSM.

MSM Gly Arg: glycerol $10 \mathrm{~g} / \mathrm{L}$, arginine $30 \mathrm{mM}$, in MSM.

TYP: tryptone $6 \mathrm{~g} / \mathrm{L}$, yeast extract $16 \mathrm{~g} / \mathrm{L}, \mathrm{NaCl} 10 \mathrm{~g} / \mathrm{L}$, in distilled water. 
ISP2 MSM: glucose $4 \mathrm{~g} / \mathrm{L}$, yeast extract $4 \mathrm{~g} / \mathrm{L}$, malt extract $10 \mathrm{~g} / \mathrm{L}$, in MSM.

ISP2 SW: glucose $4 \mathrm{~g} / \mathrm{L}$, yeast extract $4 \mathrm{~g} / \mathrm{L}$, malt extract $10 \mathrm{~g} / \mathrm{L}$, in sea water.

PPGAS: glucose $5 \mathrm{~g} / \mathrm{L}$, peptone $10 \mathrm{~g} / \mathrm{L}, \mathrm{NH}_{4} \mathrm{Cl} 20 \mathrm{mM}, \mathrm{KCl} 20 \mathrm{mM}$, Tris- $\mathrm{HCl}$ (pH 7.2) $120 \mathrm{mM}, \mathrm{MgSO}_{4} 1.6 \mathrm{mM}$, in distilled water.

MSM Glu: glucose $10 \mathrm{~g} / \mathrm{L}$ in MSM.

QUIN MSM: fructose $2 \mathrm{~g} / \mathrm{L}$, casein hydrolyzed $2 \mathrm{~g} / \mathrm{L}$, in MSM.

MSM Glu Urea: glucose $10 \mathrm{~g} / \mathrm{L}$, urea $2 \mathrm{~g} / \mathrm{L}$, in MSM.

TSB: tryptone soy broth (Condalab, Madrid, Spain) in distilled water.

\subsection{Preparation of Crude Extracts}

After 6 days, the 22 cultures were centrifuged at $6800 \times g$ at $4{ }^{\circ} \mathrm{C}$ for $30^{\prime}$. The bacterial pellet was stored at $-20^{\circ} \mathrm{C}$ for further studies, while the exhausted culture broths were subjected to organic extraction. One volume of broth was mixed with two volumes of ethyl acetate in $250 \mathrm{~mL}$ separator funnels. The organic phase was collected and evaporated using a rotavapor (R-100, BUCHI, Flawil, Switzerland) and the extracts were weighted and split for different uses as follow: $1 \mathrm{mg}$ of the extract amount was dissolved in $1 \mathrm{~mL}$ of mass grade $\mathrm{MeOH}$ for mass spectrometry analyses, while the remaining extract was dissolved in $100 \%$ DMSO at the concentration $25 \mathrm{mg} / \mathrm{mL}$ and stored at $-20{ }^{\circ} \mathrm{C}$ to be used for functional assays.

\subsection{Bioactivity Evaluation by Functional Assays}

A wide range of functional assays has been carried out to evaluate the biological effect of the 22 crude extracts.

\subsubsection{Antiviral Assays}

Virus, Cell Culture and Treatment

Vero cells ATCC CCL-81, kidney epithelial cell line from African green monkey (Cercopithecus aethiops) were purchased from American Type Culture Collection (ATCC, Manassas, VI, USA). Vero cells were grown in Dulbecco's Modified Eagle Medium (DMEM) (Microtech, Naples, Italy) supplemented with 10\% fetal bovine serum (FBS) (Microtech, Naples, Italy), $100 \mathrm{mg} / \mathrm{mL}$ of streptomycin, and $100 \mathrm{IU} / \mathrm{mL}$ of penicillin in a humidified atmosphere with $5 \% \mathrm{CO} 2$ at $37^{\circ} \mathrm{C}$. Herpes simplex virus type- 1 strain SC16 (HSV-1), Green Fluorescent Protein herpes simplex virus type 1 (HSV-1-GFP) [81], human coronavirus 229E ATCC VR-740 (HCoV-229E), human coronavirus OC43 ATCC VR-1558 (HCoV-OC43), and Poliovirus Type 1, strain Chat ATCC VR-1562 (PV-1) were purchased from ATCC and propagated on Vero cells (Table 6). The cell viability was determined through colorimetric MTT assay (see Section 4.5.3).

Table 6. Main characteristics of the viruses utilized in this work.

\begin{tabular}{cccccc}
\hline Virus & Family & Nucleic Acid & Symmetry & Envelope & Dimensions \\
\hline HSV-1/GFP & Herpesviridae & dsDNA & icosahedral & yes & $155-240 \mathrm{~nm}$ \\
HCoV-229E & Coronaviridae & ssRNA(+) & helical & yes & $80-120 \mathrm{~nm}$ \\
HCoV-OC43 & Coronoviridae & ssRNA(+) & helical & yes & $80-120 \mathrm{~nm}$ \\
PV-1 & Picornaviridae & ssRNA(+) & icosahedral & no & $30 \mathrm{~nm}$ \\
\hline
\end{tabular}

ds: double strand; ss: single strand; (+): positive strand.

\section{HSV-1 Co-Treatment Assay}

To evaluate the effect of the different samples on HSV-1 infectivity inhibition, a cotreatment experiment was performed. Vero cells were plated into 12-well cell culture plates $\left(2 \times 10^{5}\right.$ cells for well) in culture medium. The next day, the extracts were dissolved in DMEM at different concentrations, from 125 to $500 \mu \mathrm{g} / \mathrm{mL}$, in the presence of HSV- 1 at $10^{3}$ plaque forming units (PFU) and dispensed on the cells in free FBS medium for $1 \mathrm{~h}$ at $37^{\circ} \mathrm{C}$. At the end of the treatment, the cell monolayer was washed with Phosphate Buffer Saline (PBS) (Microtech, Naples, Italy) and incubated in a fresh culture medium supplemented 
with 5\% carboxymethylcellulose (CMC) (Sigma-Aldrich, Darmstadt, Germany) for $48 \mathrm{~h}$. After the incubation, the cells were fixed with $4 \%$ formaldehyde and stained with $1 \%$ crystal-violet, and the plaques were counted. The percentage of viral inhibition was calculated by counting the number of plaques obtained in presence of extract with respect to the untreated virus (CTRL-). Greco extract at $50 \mu \mathrm{g} / \mathrm{mL}$ was used as positive control (CTRL+) [25].

\section{Virus Pre-Treatment Assay}

To evaluate the effect of the fractions on HSV-1, HSV-1-GFP, HCoV-229E, and Poliovirus PV-1, a virus pre-treatment experiment was performed. Vero were plated into 12-well $\left(2 \times 10^{5}\right.$ cells/well) in culture medium and incubated for $24 \mathrm{~h}$ in a humidified atmosphere. The fractions were added at different concentrations (from 0.4 to $500 \mu \mathrm{g} / \mathrm{mL}$ ) to a viral suspension in DMEM containing $1 \times 10^{4} \mathrm{PFU}$, and incubated for $1 \mathrm{~h}$ at $37^{\circ} \mathrm{C}$. After incubation, each mixture was diluted in FBS free DMEM and titrated on Vero cells for $1 \mathrm{~h}$. Later, the cells were washed with PBS 1X and incubated for $24 \mathrm{~h}$ (HCoV-229E) or $48 \mathrm{~h}$ (HSV-1, HSV1-GFP and PV-1) in DMEM supplemented with CMC.

After 2 days, the cells were fixed and stained with 1\% crystal-violet, and the plaques were counted. Differently, after the incubation, HSV-1-GFP was not further processed, images were acquired through the Nikon ECLIPSE Ti2-U inverted florescence microscope (Nikon Europe B.V., Amsterdam, Netherlands) with beam settings for FITC and BF. The negative control is represented by the cells treated only with the virus (without sample). Pleconaril [82] at $1 \mu \mathrm{M}$ was used as positive control against PV-1, while greco extract at $50 \mu \mathrm{g} / \mathrm{mL}$ was used as positive control (CTRL+) towards the other viruses.

Antiviral Assay against Human Coronavirus (HCoV-OC43)

To verify the antiviral action against $\mathrm{HCoV}-\mathrm{OC} 43$, the inhibition of the cytopathic effect induced by the virus on the Vero cells was evaluated. Briefly, $2 \times 10^{4}$ Vero cells/well were seeded in 96-well plates and incubated for $24 \mathrm{~h}$ at $37{ }^{\circ} \mathrm{C}$ in a humidified $\mathrm{CO}_{2}(5 \%)$ atmosphere. Cell monolayers were then infected with $100 \mu \mathrm{L}$ of a proper virus dilution in a maintenance medium. At the same time, $100 \mu \mathrm{L}$ of medium, without or with serial dilutions of the tested compounds, were added. Greco extract at $50 \mu \mathrm{g} / \mathrm{mL}$ was used as positive control. After 3 days of incubation at $37^{\circ} \mathrm{C}$, cell viability was determined by the MTT assay (see Section 4.5.3).

\subsubsection{Antiproliferative Assays}

\section{Maintenance of Human Cell Cultures}

The human prostatic adenocarcinoma cell line (PC3) and the human prostatic epithelial cell line (PNT2) were maintained using RPMI 1640 medium supplemented with 10\% $(v / v)$ fetal bovine serum (FBS), $2 \mathrm{mM}$ L-glutamine, 100 units $/ \mathrm{mL}$ penicillin and $100 \mu \mathrm{g} / \mathrm{mL}$ streptomycin. Cells were grown in a $5 \% \mathrm{CO} 2$ atmosphere at $37^{\circ} \mathrm{C}$, maintaining confluence under $70 \%$.

\section{Cytotoxicity Assay}

Cells $\left(2 \times 10^{3}\right.$ cells/well, $100 \mu \mathrm{L}$ final volume) were seeded in 96-well plates and kept overnight for attachment for cytotoxicity assessment. DMSO was used at a final concentration of $\leq 0.5 \%(v / v)$ for each treatment. Cells were treated in biological triplicate with 1,10 , and $100 \mu \mathrm{g} / \mathrm{mL}$ of extracts for $48 \mathrm{~h}$ in a complete cell medium. At the end of incubation with the samples, cytotoxicity was evaluated by MTT assay (see Section 4.5.3). Untreated cells were used as negative control.

\subsubsection{MTT Assay}

MTT assay was used to assess cell viability after antiproliferative and antiviral treatments using the Thiazolyl Blue Tetrazolium Bromide [3-(4,5-dimethylthiazol-2-yl)-2,5diphenyltetrazolium bromide] (Sigma-Aldrich, Darmstadt, Germany). After treatment, the 
supernatant was removed and $0.5 \mathrm{mg} / \mathrm{mL}$ of MTT water solution was added to the cells for $3 \mathrm{~h}$. After emptying the plate, $100 \mu \mathrm{L}$ of DMSO were added in each well to solubilize the formazan crystals. Finally, the absorbance was read at $570 \mathrm{~nm}$ with a microplate reader. The control is represented by untreated cells.

\subsubsection{Biosurfactant Screening Assay by CTAB Agar Method}

The CTAB agar method, also called Blue agar, is an in-plate test that can reveal the presence of anionic biosurfactants by the arising of dark blue halos around the extracts. In this method, the anionic biosurfactants form an insoluble complex with cetyltrimethylammonium bromide, and the complex is revealed by the presence of methylene blue. $4 \mu \mathrm{L}$ of the extracts, dissolved in DMSO at $25 \mathrm{mg} / \mathrm{mL}$ were spotted on the blue agar plates. As a negative control, $8 \mu \mathrm{L}$ of pure DMSO were used, while $4 \mu \mathrm{L}$ of $0.1 \%$ and $0.01 \%$ sodium dodecyl sulphate (SDS) were used as positive controls. After 2 days at $4{ }^{\circ} \mathrm{C}$, the extracts containing biosurfactants were selected by the presence of a dark blue halo around the wells.

\subsection{Chemical Profiling by Mass Spectrometry and Molecular Networking}

The extracts obtained in the 22 different media were dissolved in mass grade $\mathrm{MeOH}$ and subjected to a liquid chromatography-mass-spectrometry analysis by performing a low-resolution mass spectrometry (LRMS) data-dependent analysis. The chromatographic separation was achieved on a Synergi $2.5 \mathrm{~mm}$ Fusion_RP $100 \times 2$ by using a 20 min linear gradient from $0 \%$ to $100 \%$ of buffer B (Buffer A: H2O + 0.1\% Formic acid, Buffer B: ACN $+0.1 \%$ Formic acid). Mass spectra were recorded in positive and negative mode within a mass range of 150-1500 Da, and the most abundant ions were subjected to MS/MS fragmentation with a rolling collision energy between $0-80 \mathrm{eV}$.

Low-resolution MS/MS data from the 22 crude extracts were converted to *.mzXML by using the tool msconvert from ProteoWizard [83] and imported into MZmine 2.53. Mass detection was performed on .mzXML data and centroided masses with mass level 1 and mass level 2, by keeping the noise level at 1000 and 100, respectively. Chromatograms were built using the ADAP chromatogram algorithm [84] with a minimum height of 1000, and $m / z$ tolerance of 1 . For chromatogram deconvolution, the baseline cut-off algorithm was employed with the following settings: minimum height peak $=1000$, peak duration range $=0.0-3.0 \mathrm{~min}$, baseline level $=100, \mathrm{~m} / \mathrm{z}$ range for MS2 scan $=1$, retention time range $=0.15 \mathrm{~min} .\left[\mathrm{M}+1,{ }^{13} \mathrm{C}\right]$ adducts were filtered out using the "isotopic peaks grouper" module, by setting $\mathrm{m} / \mathrm{z}$ tolerance at 0.1 and and $R_{t}$ tolerance at $0.1 \mathrm{~min}$. Peak alignment was performed using the Join aligner algorithm $\left(\mathrm{m} / z\right.$ tolerance at 0.5 , absolute $R_{t}$ tolerance at $0.6 \mathrm{~min}$ ). Peaks without associated MS/MS spectrum were finally filtered out from the peak list. Clustered data were then exported to .mgf file for GNPS, while chromatographic information of each peak was exported to a quantification table as .csv format file. Processed data were submitted to GNPS [8] to create a molecular network by using the Feature Based Molecular Networking (FBMN) tool [28]. FBMN parameters were set as follows: precursor ion mass and fragment ion mass tolerances $=0.5 \mathrm{Da}$, cosine score $\geq 0.7$, minimum matched fragment ions $=4$. The molecular network (available at https: / /gnps.ucsd.edu/ ProteoSAFe/status.jsp?task=c8ae043f75914cbcadf441d283670291, accessed on 1 April 2021) was visualized and analyzed in Cytoscape 3.7.2. Chromatographic data in the .csv file were mapped to the relevant nodes in the generated network.

\subsection{Scale-Up Fermentation of I2R in SV2 SW Medium and Crude Extract Fractionation}

Rhodococcus sp. I2R was grown in $400 \mathrm{~mL}$ of SV2 SW medium for 6 days at $20^{\circ} \mathrm{C}$; then, the culture broth was extracted with 2 volumes of ethyl acetate. Subsequently, the crude extract was fractionated with a Chromabond SPE C18 column Cartridge (Macherey-Nagel, Duren, Germany). Elution was performed stepwise with an increasing methanol concentration. The gradient was selected based on the spectra derived from mass spectrometry analysis. Gradient: $\mathrm{H}_{2} \mathrm{O}, 50 \% \mathrm{MeOH}, 90 \% \mathrm{MeOH}, 100 \% \mathrm{MeOH}$. The three eluted fractions 
(water excluded) were collected, dried and dissolved in DMSO at stock concentration of $25 \mathrm{mg} / \mathrm{mL}$ to perform the antiviral, antiproliferative, and biosurfactant assay.

\subsection{Data-Dependent LC-HRMS/MS Analysis of the $90 \% \mathrm{MeOH}$ Fraction}

The $90 \% \mathrm{MeOH}$ from the crude extract of Rhodococcus sp. I2R cultivated in SV2 SW was dried under vacuum and dissolved in $\mathrm{MeOH}$ at a concentration of $1 \mathrm{mg} / \mathrm{mL}$ for LC-HRMS/MS (Liquid Chromatography_High Resolution Tandem Mass Spectrometry) analyses, as previously reported [85]. Experiments were performed using a Thermo LTQ Orbitrap XL high-resolution ESI mass spectrometer coupled to a Thermo U3000 HPLC system, which included a solvent reservoir, in-line degasser, binary pump, and refrigerated autosampler. A 5- $\mu \mathrm{m}$ Kinetex C18 column $(50 \times 2.10 \mathrm{~mm})$, maintained at room temperature, was eluted at $200 \mu \mathrm{L} \cdot \mathrm{min}^{-1}$ with $\mathrm{H}_{2} \mathrm{O}$ (supplemented with $0.1 \% \mathrm{HCOOH}$ ) and $\mathrm{CH}_{3} \mathrm{CN}$, using a gradient elution. The gradient program was set as follows: $5 \% \mathrm{CH}_{3} \mathrm{CN} 3 \mathrm{~min}, 5-99 \%$ $\mathrm{CH}_{3} \mathrm{CN}$ over $30 \mathrm{~min}, 100 \% \mathrm{CH}_{3} \mathrm{CN} 7 \mathrm{~min}$. A survey full MS scan was acquired in positive and negative ion detection modes. MS parameters were a spray voltage of $4.8 \mathrm{kV}$, a capillary temperature of $285^{\circ} \mathrm{C}$, a sheath gas rate of 32 units $\mathrm{N}_{2}$ (ca. $150 \mathrm{~mL} / \mathrm{min}$ ), and an auxiliary gas rate of 15 units $\mathrm{N}_{2}$ (ca. $50 \mathrm{~mL} / \mathrm{min}$ ). Data were collected in the data-dependent acquisition mode to perform high resolution tandem mass spectrometry (HRMS/MS) analysis of selected ions reported in Table 1 , in negative ion detection mode. The $\mathrm{m} / \mathrm{z}$ range for data-dependent acquisition was set between $100 \mathrm{and} 2000 \mathrm{amu}$. HRMS/MS scans were obtained for selected ions with CID fragmentation, an isolation width of 2.0, normalized collision energy of 35 , activation $Q$ of 0.250 , and an activation time of $30 \mathrm{~ms}$.

\subsection{Methanolysis of the $90 \% \mathrm{MeOH}$ Fraction and GC-MS Analysis of FAMEs}

The $90 \% \mathrm{MeOH}$ fraction $(800 \mu \mathrm{g})$ from crude extract SV2 SW, was dissolved in $6 \mathrm{M}$ $\mathrm{HCl}(500 \mu \mathrm{L})$ and kept at $90^{\circ} \mathrm{C}$ for $16 \mathrm{~h}$. The hydrolysis product was dried under nitrogen, then $500 \mu \mathrm{L} \mathrm{CHCl}_{3}, 450 \mu \mathrm{L} \mathrm{MeOH}$, and $75 \mu \mathrm{L} \mathrm{H}_{2} \mathrm{SO}_{4}$ were added and the reaction mixture was incubated again at $90^{\circ} \mathrm{C}$ for $16 \mathrm{~h}$ to yield fatty acid methyl esters (FAMEs), according to a slightly modified protocol reported in the literature [86]. After cooling to room temperature, an equal volume of distilled water was added, and then time was allowed for phase separation. The lower phase, which contained FAMEs, was collected and dried under nitrogen. FAMEs were analyzed by GC/MS on a 5390 MSD quadrupole mass spectrometer (Agilent, Cernusco sul Naviglio, Milano, Italy), using an HP-5MS capillary column (Agilent, $5 \%$ Phenyl Methyl Siloxane) (30 m length, $0.25 \mathrm{~mm} \varnothing, 0.25 \mu \mathrm{m}$ film). Helium was used as a carrier gas, injection was in split mode, and the program was as follows: hold $50{ }^{\circ} \mathrm{C}$ for $1 \mathrm{~min}$, heat to $140{ }^{\circ} \mathrm{C}$ with $8^{\circ} \mathrm{C} / \mathrm{min}$, hold $140^{\circ} \mathrm{C}$ for $2 \mathrm{~min}$, heat to $180^{\circ} \mathrm{C}$ with $5^{\circ} \mathrm{C} / \mathrm{min}$, heat to $280^{\circ} \mathrm{C}$ with $10^{\circ} \mathrm{C} / \mathrm{min}$, hold $280^{\circ} \mathrm{C}$ for $5 \mathrm{~min}$.

\subsection{Statistical Analysis}

Bioassay data represent the mean ( \pm standard deviation, $S D$ ) of at least three independent experiments. Differences between groups were determined by analysis of variance (ANOVA) and were considered statistically significant at $p<0.05$. Statistical analysis was performed using the GraphPad Prism Software Version 8 (GraphPad Software Inc., San Diego, CA, USA).

\section{Conclusions}

The marine environment is a promising source for a large variety of surface-active metabolites. Undoubtedly, their chemical diversity is much larger than described until today and the structures of many biosurfactants still remain unknown. Herein, once again, Actinobacteria clearly have been shown to be a unique and vast untapped resource for the discovery of novel and potentially useful biosurfactants. The application of an OSMAC approach, combined with a highly metabolically versatile bacterium and the use of LC-HRMS/MS, allowed the production and identification of a complex extracellular mixture of novel succinic saccharide esters with an uncommon functional group, i.e., 
phenylacetic acid. For the first time, we observed the antiviral effects of these glycolipid molecules against coronaviruses, leading to virus inactivation likely through a detergentlike mechanism. Due to the high complexity of the active fraction, the antiviral assays were carried out on the mixture. Future perspectives will include (a) optimization of culture conditions to favor the production of a specific class of biosurfactants, (b) purification of single molecules for NMR stereo-structural elucidation, and (c) characterization of the biosynthetic pathways for succinoyl saccharide esters through transcriptomic analysis and functional genomics studies.

Supplementary Materials: The following are available online at https:/ / www.mdpi.com/article/10 $.3390 / \mathrm{ijms} 22169055 / \mathrm{s} 1$.

Author Contributions: Conceptualization, F.P.E., R.G., G.D.S.; investigation and formal analysis, F.P.E., R.G., G.D.S., C.G., J.A., C.B. and G.A.V.; data curation, F.P.E., R.G., G.D.S., C.B.; writing-original draft preparation, F.P.E., R.G., G.D.S. and D.d.P.; writing and editing, F.P.E., R.G., G.D.S., C.G., C.B. and D.d.P. supervision, G.D.S., D.C., G.F., M.G., D.d.P.; funding acquisition, D.d.P. All authors have read and agreed to the published version of the manuscript.

Funding: This research was funded by H2020-FNR-11-2020: SECRETED, grant number 101000794.

Institutional Review Board Statement: Not applicable.

Informed Consent Statement: Not applicable.

Data Availability Statement: Not applicable.

Acknowledgments: The authors are grateful to PRIN 2017 "Natural and pharmacological inhibition of the early phase of viral replication (VirSudNet)" No.2017M8R7N9.

Conflicts of Interest: The authors declare no conflict of interest.

\section{References}

1. Naughton, L.M.; Romano, S.; O'Gara, F.; Dobson, A.D.W. Identification of Secondary Metabolite Gene Clusters in the Pseudovibrio Genus Reveals Encouraging Biosynthetic Potential toward the Production of Novel Bioactive Compounds. Front. Microbiol. 2017, 8, 1494. [CrossRef]

2. Reen, F.J.; Romano, S.; Dobson, A.D.W.; O'Gara, F. The Sound of Silence: Activating Silent Biosynthetic Gene Clusters in Marine Microorganisms. Mar. Drugs 2015, 13, 4754-4783. [CrossRef] [PubMed]

3. Medema, M.H.; Blin, K.; Cimermancic, P.; de Jager, V.; Zakrzewski, P.; Fischbach, M.A.; Weber, T.; Takano, E.; Breitling, R. antiSMASH: Rapid identification, annotation and analysis of secondary metabolite biosynthesis gene clusters in bacterial and fungal genome sequences. Nucleic Acids Res. 2011, 39 (Suppl. 2), W339-W346. [CrossRef] [PubMed]

4. Blin, K.; Shaw, S.; Steinke, K.; Villebro, R.; Ziemert, N.; Lee, S.Y.; Medema, M.H.; Weber, T. antiSMASH 5.0: Updates to the secondary metabolite genome mining pipeline. Nucleic Acids Res. 2019, 47, W81-W87. [CrossRef] [PubMed]

5. Gram, L. Silent clusters - speak up! Microb. Biotechnol. 2015, 8, 13-14. [CrossRef]

6. van der Hooft, J.J.J.; Mohimani, H.; Bauermeister, A.; Dorrestein, P.C.; Duncan, K.R.; Medema, M.H. Linking genomics and metabolomics to chart specialized metabolic diversity. Chem. Soc. Rev. 2020, 49, 3297-3314. [CrossRef]

7. Romano, S.; Jackson, S.A.; Patry, S.; Dobson, A.D.W. Extending the “One Strain Many Compounds" (OSMAC) Principle to Marine Microorganisms. Mar. Drugs 2018, 16, 244. [CrossRef] [PubMed]

8. Wang, M.; Carver, J.J.; Phelan, V.V.; Sanchez, L.M.; Garg, N.; Peng, Y.; Nguyen, D.D.; Watrous, J.; Kapono, C.A.; Luzzatto-Knaan, T.; et al. Sharing and community curation of mass spectrometry data with Global Natural Products Social Molecular Networking. Nat. Biotechnol. 2016, 34, 828-837. [CrossRef]

9. Paulino, B.N.; Pessôa, M.G.; Mano, M.C.; Molina, G.; Neri-Numa, I.A.; Pastore, G.M. Current status in biotechnological production and applications of glycolipid biosurfactants. Appl. Microbiol. Biotechnol. 2016, 100, 10265-10293. [CrossRef]

10. Jezierska, S.; Claus, S.; Van Bogaert, I. Yeast glycolipid biosurfactants. FEBS Lett. 2018, 592, 1312-1329. [CrossRef]

11. Olasanmi, I.O.; Thring, R.W. The Role of Biosurfactants in the Continued Drive for Environmental Sustainability. Sustainability 2018, 10, 4817. [CrossRef]

12. Hameş Tuna, E.E.; Fazilet, V.-S.; Kosaric, N. Patents on Biosurfactants and Future Trends. Biosurfactants Prod. Util.-Process. Technol. Econ. 2014, 159, 165. [CrossRef]

13. Franzetti, A.; Gandolfi, I.; Bestetti, G.; Smyth, T.J.P.; Banat, I.M. Production and applications of trehalose lipid biosurfactants. Eur. J. Lipid Sci. Technol. 2010, 112, 617-627. [CrossRef]

14. Cappelletti, M.; Presentato, A.; Piacenza, E.; Firrincieli, A.; Turner, R.J.; Zannoni, D. Biotechnology of Rhodococcus for the production of valuable compounds. Appl. Microbiol. Biotechnol. 2020, 104, 8567-8594. [CrossRef] [PubMed] 
15. Banat, I.M.; Franzetti, A.; Gandolfi, I.; Bestetti, G.; Martinotti, M.G.; Fracchia, L.; Smyth, T.J.; Marchant, R. Microbial biosurfactants production, applications and future potential. Appl Microbiol Biotechnol 2010, 87, 427-444. [CrossRef] [PubMed]

16. Figueras, M.J.; Beaz-Hidalgo, R.; Hossain, M.J.; Liles, M.R. Taxonomic affiliation of new genomes should be verified using average nucleotide identity and multilocus phylogenetic analysis. Genome Announc. 2014, 2, e00927-14. [CrossRef]

17. Overbeek, R.; Olson, R.; Pusch, G.D.; Olsen, G.J.; Davis, J.J.; Disz, T.; Edwards, R.A.; Gerdes, S.; Parrello, B.; Shukla, M.; et al. The SEED and the Rapid Annotation of microbial genomes using Subsystems Technology (RAST). Nucleic Acids Res. 2013, 42, D206-D214. [CrossRef]

18. Garrido-Sanz, D.; Redondo-Nieto, M.; Martín, M.; Rivilla, R. Comparative Genomics of the Rhodococcus Genus Shows Wide Distribution of Biodegradation Traits. Microorganisms 2020, 8, 774. [CrossRef]

19. Peng, T.; Kan, J.; Hu, J.; Hu, Z. Genes and novel sRNAs involved in PAHs degradation in marine bacteria Rhodococcus sp. P14 revealed by the genome and transcriptome analysis. 3 Biotech 2020, 10, 140. [CrossRef]

20. Garrido-Sanz, D.; Sansegundo-Lobato, P.; Redondo-Nieto, M.; Suman, J.; Cajthaml, T.; Blanco-Romero, E.; Martin, M.; Uhlik, O.; Rivilla, R. Analysis of the biodegradative and adaptive potential of the novel polychlorinated biphenyl degrader Rhodococcus sp. WAY2 revealed by its complete genome sequence. Microb. Genom. 2020, 6, e000363. [CrossRef]

21. Nachtigall, J.; Schneider, K.; Nicholson, G.; Goodfellow, M.; Zinecker, H.; Imhoff, J.F.; Süssmuth, R.D.; Fiedler, H.-P. Two new aurachins from Rhodococcus sp. Acta 2259. J. Antibiot. 2010, 63, 567-569. [CrossRef]

22. Schneemann, I.; Kajahn, I.; Ohlendorf, B.; Zinecker, H.; Erhard, A.; Nagel, K.; Wiese, J.; Imhoff, J.F. Mayamycin, a Cytotoxic Polyketide from a Streptomyces Strain Isolated from the Marine Sponge Halichondria panicea. J. Nat. Prod. 2010, 73, 1309-1312. [CrossRef] [PubMed]

23. Amos, G.C.A.; Awakawa, T.; Tuttle, R.N.; Letzel, A.C.; Kim, M.C.; Kudo, Y.; Fenical, W.; Moore, B.S.; Jensen, P.R. Comparative transcriptomics as a guide to natural product discovery and biosynthetic gene cluster functionality. Proc. Natl. Acad. Sci. USA 2017, 114, E11121-E11130. [CrossRef] [PubMed]

24. Engelhardt, K.; Degnes, K.F.; Kemmler, M.; Bredholt, H.; Fjaervik, E.; Klinkenberg, G.; Sletta, H.; Ellingsen, T.E.; Zotchev, S.B. Production of a new thiopeptide antibiotic, TP-1161, by a marine Nocardiopsis species. Appl. Environ. Microbiol. 2010, 76, 4969-4976. [CrossRef] [PubMed]

25. Zannella, C.; Giugliano, R.; Chianese, A.; Buonocore, C.; Vitale, G.A.; Sanna, G.; Sarno, F.; Manzin, A.; Nebbioso, A.; Termolino, P.; et al. Antiviral Activity of Vitis vinifera Leaf Extract against SARS-CoV-2 and HSV-1. Viruses 2021, 13, 1263. [CrossRef] [PubMed]

26. Buonocore, C.; Tedesco, P.; Vitale, G.A.; Palma Esposito, F.; Giugliano, R.; Monti, M.C.; D'Auria, M.V.; de Pascale, D. Characterization of a New Mixture of Mono-Rhamnolipids Produced by Pseudomonas gessardii Isolated from Edmonson Point (Antarctica). Mar. Drugs 2020, 18, 269. [CrossRef]

27. Pluskal, T.; Castillo, S.; Villar-Briones, A.; Oresic, M. MZmine 2: Modular framework for processing, visualizing, and analyzing mass spectrometry-based molecular profile data. BMC Bioinform. 2010, 11, 395. [CrossRef]

28. Nothias, L.F.; Petras, D.; Schmid, R.; Dührkop, K.; Rainer, J.; Sarvepalli, A.; Protsyuk, I.; Ernst, M.; Tsugawa, H.; Fleischauer, M.; et al. Feature-based molecular networking in the GNPS analysis environment. Nat. Methods 2020, 17, 905-908. [CrossRef]

29. Esch, S.W.; Morton, M.D.; Williams, T.D.; Buller, C.S. A novel trisaccharide glycolipid biosurfactant containing trehalose bears ester-linked hexanoate, succinate, and acyloxyacyl moieties: NMR and MS characterization of the underivatized structure. Carbohydr. Res. 1999, 319, 112-123. [CrossRef]

30. Konishi, M.; Nishi, S.; Fukuoka, T.; Kitamoto, D.; Watsuji, T.-O.; Nagano, Y.; Yabuki, A.; Nakagawa, S.; Hatada, Y.; Horiuchi, J.-I. Deep-sea Rhodococcus sp. BS-15, Lacking the Phytopathogenic fas Genes, Produces a Novel Glucotriose Lipid Biosurfactant. Mar. Biotechnol. 2014, 16, 484-493. [CrossRef]

31. Kügler, J.H.; Le Roes-Hill, M.; Syldatk, C.; Hausmann, R. Surfactants tailored by the class Actinobacteria. Front. Microbiol. 2015, 6, 212. [CrossRef] [PubMed]

32. Demarque, D.P.; Crotti, A.E.M.; Vessecchi, R.; Lopes, J.L.C.; Lopes, N.P. Fragmentation reactions using electrospray ionization mass spectrometry: An important tool for the structural elucidation and characterization of synthetic and natural products. Nat. Prod. Rep. 2016, 33, 432-455. [CrossRef]

33. Li, J.; Xu, J.; Zhang, R.; Hao, Y.; He, J.; Chen, Y.; Jiao, G.; Abliz, Z. Strategy for Global Profiling and Identification of 2- and 3-Hydroxy Fatty Acids in Plasma by UPLC-MS/MS. Anal. Chem. 2020, 92, 5143-5151. [CrossRef] [PubMed]

34. Fautz, E.; Rosenfelder, G.; Grotjahn, L. Iso-branched 2- and 3-hydroxy fatty acids as characteristic lipid constituents of some gliding bacteria. J. Bacteriol. 1979, 140, 852-858. [CrossRef]

35. The Lipid Web. Available online: https://www.lipidmaps.org/resources/lipidweb (accessed on 16 June 2021).

36. CHEMDATA.NIST.GOV. Available online: https:/ / chemdata.nist.gov (accessed on 16 June 2021).

37. Alvarez, H.M.; Luftmann, H.; Silva, R.A.; Cesari, A.C.; Viale, A.; Wältermann, M.; Steinbüchel, A. Identification of phenyldecanoic acid as a constituent of triacylglycerols and wax ester produced by Rhodococcus opacus PD630. Microbiology 2002, 148, 1407-1412. [CrossRef] [PubMed]

38. Jae-Jun, S.; Mun-Hwan, C.; Sung-Chul, Y. Cometabolism of $\omega$-Phenylalkanoic Acids with Butyric Acid for Efficient Production of Aromatic Polyesters in Pseudomonas putida BM01. J. Microbiol. Biotechnol. 2001, 11, 435-442.

39. Tischler, D.; Niescher, S.; Kaschabek, S.R.; Schlömann, M. Trehalose phosphate synthases OtsA1 and OtsA2 of Rhodococcus opacus 1CP. FEMS Microbiol. Lett. 2013, 342, 113-122. [CrossRef] [PubMed] 
40. Retamal-Morales, G.; Heine, T.; Tischler, J.S.; Erler, B.; Gröning, J.A.D.; Kaschabek, S.R.; Schlömann, M.; Levicán, G.; Tischler, D. Draft genome sequence of Rhodococcus erythropolis B7g, a biosurfactant producing actinobacterium. J. Biotechnol. 2018, 280, 38-41. [CrossRef]

41. Delegan, Y.; Sargsyan, A.; Hovhannisyan, N.; Babayan, B.; Petrikov, K.; Vainstein, M. Analysis of genome sequence and trehalose lipid production peculiarities of the thermotolerant Gordonia strain. J. Basic Microbiol. 2020, 60, 14-21. [CrossRef] [PubMed]

42. Inaba, T.; Tokumoto, Y.; Miyazaki, Y.; Inoue, N.; Maseda, H.; Nakajima-Kambe, T.; Uchiyama, H.; Nomura, N. Analysis of genes for succinoyl trehalose lipid production and increasing production in Rhodococcus sp. strain SD-74. Appl. Environ. Microbiol. 2013, 79, 7082-7090. [CrossRef]

43. Palčeková, Z.; Angala, S.K.; Belardinelli, J.M.; Eskandarian, H.A.; Joe, M.; Brunton, R.; Rithner, C.; Jones, V.; Nigou, J.; Lowary, T.L.; et al. Disruption of the SucT acyltransferase in Mycobacterium smegmatis abrogates succinylation of cell envelope polysaccharides. J. Biol. Chem. 2019, 294, 10325-10335. [CrossRef]

44. Schorn, M.A.; Alanjary, M.M.; Aguinaldo, K.; Korobeynikov, A.; Podell, S.; Patin, N.; Lincecum, T.; Jensen, P.R.; Ziemert, N.; Moore, B.S. Sequencing rare marine actinomycete genomes reveals high density of unique natural product biosynthetic gene clusters. Sequencing rare marine actinomycete genomes reveals high density of unique natural product biosynthetic gene clusters. Microbiology 2016, 162, 2075-2086. [CrossRef]

45. Soldatou, S.; Eldjárn, G.H.; Ramsay, A.; van der Hooft, J.J.J.; Hughes, A.H.; Rogers, S.; Duncan, K.R. Comparative Metabologenomics Analysis of Polar Actinomycetes. Mar. Drugs 2021, 19, 103. [CrossRef]

46. Pan, R.; Bai, X.; Chen, J.; Zhang, H.; Wang, H. Exploring Structural Diversity of Microbe Secondary Metabolites Using OSMAC Strategy: A Literature Review. Front. Microbiol. 2019, 10, 294. [CrossRef]

47. Schwarz, J.; Hubmann, G.; Rosenthal, K.; Lütz, S. Triaging of Culture Conditions for Enhanced Secondary Metabolite Diversity from Different Bacteria. Biomolecules 2021, 11, 193. [CrossRef] [PubMed]

48. Vitale, G.A.; Sciarretta, M.; Cassiano, C.; Buonocore, C.; Festa, C.; Mazzella, V.; Núñez Pons, L.; D’Auria, M.V.; de Pascale, D. Molecular Network and Culture Media Variation Reveal a Complex Metabolic Profile in Pantoea cf. eucrina D2 Associated with an Acidified Marine Sponge. Int. J. Mol. Sci. 2020, 21, 6307. [CrossRef] [PubMed]

49. Della Sala, G.; Teta, R.; Esposito, G.; Pawlik, J.R.; Mangoni, A.; Costantino, V. Zeamide, a Glycosylinositol Phosphorylceramide with the Novel Core Arap $(1 \beta \rightarrow 6)$ Ins Motif from the Marine Sponge Svenzea zeai. Molecules 2017, 22, 1455. [CrossRef] [PubMed]

50. Henkel, M.; Müller, M.M.; Kügler, J.H.; Lovaglio, R.B.; Contiero, J.; Syldatk, C.; Hausmann, R. Rhamnolipids as biosurfactants from renewable resources: Concepts for next-generation rhamnolipid production. Process Biochem. 2012, 47, 1207-1219. [CrossRef]

51. Marchant, R.; Banat, I.M. Biosurfactants: A sustainable replacement for chemical surfactants? Biotechnol. Lett. 2012, 34, 1597-1605. [CrossRef]

52. Tedesco, P.; Maida, I.; Palma Esposito, F.; Tortorella, E.; Subko, K.; Ezeofor, C.C.; Zhang, Y.; Tabudravu, J.; Jaspars, M.; Fani, R.; et al. Antimicrobial Activity of Monoramnholipids Produced by Bacterial Strains Isolated from the Ross Sea (Antarctica). Mar. Drugs 2016, 14, 83. [CrossRef]

53. Chianese, G.; Esposito, F.P.; Parrot, D.; Ingham, C.; De Pascale, D.; Tasdemir, D. Linear Aminolipids with Moderate Antimicrobial Activity from the Antarctic Gram-Negative Bacterium Aequorivita sp. Mar. Drugs 2018, 16, 187. [CrossRef] [PubMed]

54. Onwosi, C.O.; Aliyu, G.O.; Onu, C.J.; Chukwu, K.O.; Ndukwe, J.K.; Igbokwe, V.C. Microbial-derived glycolipids in the sustainable formulation of biomedical and personal care products: A consideration of the process economics towards commercialization Process Biochem. 2021, 100, 124-139. [CrossRef]

55. Tokumoto, Y.; Nomura, N.; Uchiyama, H.; Imura, T.; Morita, T.; Fukuoka, T.; Kitamoto, D. Structural characterization and surfaceactive properties of a succinoyl trehalose lipid produced by Rhodococcus sp. SD-74. J. Oleo Sci. 2009, 58, 97-102. [CrossRef] [PubMed]

56. Silva, S.N.R.L.; Farias, C.B.B.; Rufino, R.D.; Luna, J.M.; Sarubbo, L.A. Glycerol as substrate for the production of biosurfactant by Pseudomonas aeruginosa UCP0992. Colloids Surf. B Biointerfaces 2010, 79, 174-183. [CrossRef] [PubMed]

57. Putri, M.; Hertadi, R. Effect of Glycerol as Carbon Source for Biosurfactant Production by Halophilic Bacteria Pseudomonas Stutzeri BK-AB12. Procedia Chem. 2015, 16, 321-327. [CrossRef]

58. Ciapina, E.M.; Melo, W.C.; Santa Anna, L.M.; Santos, A.S.; Freire, D.M.; Pereira, N., Jr. Biosurfactant production by Rhodococcus erythropolis grown on glycerol as sole carbon source. Appl. Biochem. Biotechnol. 2006, 131, 880-886. [CrossRef]

59. Giri, S.S.; Kim, H.J.; Kim, S.G.; Kim, S.W.; Kwon, J.; Lee, S.B.; Park, S.C. Immunomodulatory Role of Microbial Surfactants, with Special Emphasis on Fish. Int. J. Mol. Sci. 2020, 21, 7004. [CrossRef]

60. Christova, N.; Lang, S.; Wray, V.; Kaloyanov, K.; Konstantinov, S.; Stoineva, I. Production, Structural Elucidation, and In Vitro Antitumor Activity of Trehalose Lipid Biosurfactant from Nocardia farcinica Strain. J. Microbiol. Biotechnol. $2015,25,439-447$. [CrossRef]

61. Vollenbroich, D.; Ozel, M.; Vater, J.; Kamp, R.M.; Pauli, G. Mechanism of inactivation of enveloped viruses by the biosurfactant surfactin from Bacillus subtilis. Biol. J. Int. Assoc. Biol. Stand. 1997, 25, 289-297. [CrossRef]

62. Jung, M.; Lee, S.; Kim, H. Recent studies on natural products as anti-HIV agents. Curr. Med. Chem. 2000, 7, 649-661. [CrossRef]

63. Seydlová, G.; Svobodová, J. Review of surfactin chemical properties and the potential biomedical applications. Cent. Eur. J. Med. 2008, 3, 123-133. [CrossRef]

64. Lang, S.; Wagner, F. Biological activities of biosurfactants. In Biosurfactants: Production-Properties-Applications; Kosaric, N., Ed.; CRC Press: Boca Raton, FL, USA, 1993; Volume 48, pp. 251-268. 
65. Uchida, Y.; Tsuchiya, R.; Chino, M.; Hirano, J.; Tabuchi, T.J.A. Extracellular Accumulation of Mono- and Di-Succinoyl Trehalose Lipids by a Strain of Rhodococcus erythropolis Grown on n-Alkanes. Agric. Biol. Chem. 1989, 53, 757-763. [CrossRef]

66. Uchida, Y.; Misawa, S.; Nakahara, T.; Tabuchi, T. Factors Affecting the Production of Succinoyl Trehalose Lipids by Rhodococcus erythropolis SD-74 Grown on n-Alkanes. Agric. Biol. Chem. 1989, 53, 765-769. [CrossRef]

67. Hoq, M.M.; Suzutani, T.; Toyoda, T.; Horiike, G.; Yoshida, I.; Azuma, M. Role of gamma delta TCR+ lymphocytes in the augmented resistance of trehalose 6,6'-dimycolate-treated mice to influenza virus infection. J. Gen. Virol. 1997, 78, 1597-1603. [CrossRef]

68. Azuma, M.; Suzutani, T.; Sazaki, K.; Yoshida, I.; Sakuma, T.; Yoshida, T. Role of interferon in the augmented resistance of trehalose-6,6'-dimycolate-treated mice to influenza virus infection. J. Gen. Virol. 1987, 68, 835-843. [CrossRef]

69. Weisburg, W.G.; Barns, S.M.; Pelletier, D.A.; Lane, D.J. 16 S ribosomal DNA amplification for phylogenetic study. J. Bacteriol. 1991, 173, 697-703. [CrossRef]

70. Huang, X.; Madan, A. CAP3: A DNA sequence assembly program. Genome Res. 1999, 9, 868-877. [CrossRef]

71. Bolger, A.M.; Lohse, M.; Usadel, B. Trimmomatic: A flexible trimmer for Illumina sequence data. Bioinformatics 2014, 30, 2114-2120. [CrossRef]

72. Andrews, S. FastQC: A Quality Control Tool for High Throughput Sequence Data. Available online: http://www.bioinformatics. babraham.ac.uk/projects/fastqc (accessed on 1 September 2020).

73. Marçais, G.; Kingsford, C. A fast, lock-free approach for efficient parallel counting of occurrences of k-mers. Bioinformatics 2011, 27, 764-770. [CrossRef]

74. Bankevich, A.; Nurk, S.; Antipov, D.; Gurevich, A.A.; Dvorkin, M.; Kulikov, A.S.; Lesin, V.M.; Nikolenko, S.I.; Pham, S.; Prjibelski, A.D.; et al. SPAdes: A new genome assembly algorithm and its applications to single-cell sequencing. J. Comput. Biol. 2012, 19, 455-477. [CrossRef]

75. Waterhouse, R.M.; Seppey, M.; Simão, F.A.; Manni, M.; Ioannidis, P.; Klioutchnikov, G.; Kriventseva, E.V.; Zdobnov, E.M. BUSCO Applications from Quality Assessments to Gene Prediction and Phylogenomics. Mol. Biol. Evol. 2017, 35, 543-548. [CrossRef]

76. Yoon, S.H.; Ha, S.M.; Lim, J.; Kwon, S.; Chun, J. A large-scale evaluation of algorithms to calculate average nucleotide identity. Antonie van Leeuwenhoek 2017, 110, 1281-1286. [CrossRef]

77. Seemann, T. Prokka: Rapid prokaryotic genome annotation. Bioinformatics 2014, 30, 2068-2069. [CrossRef]

78. Arkin, A.P.; Cottingham, R.W.; Henry, C.S.; Harris, N.L.; Stevens, R.L.; Maslov, S.; Dehal, P.; Ware, D.; Perez, F.; Canon, S.; et al. KBase: The United States Department of Energy Systems Biology Knowledgebase. Nat. Biotechnol. 2018, 36, 566-569. [CrossRef]

79. Kanehisa, M.; Sato, Y. KEGG Mapper for inferring cellular functions from protein sequences. Protein Sci. 2020, 29, 28-35. [CrossRef]

80. Blin, K.; Shaw, S.; Kloosterman, A.M.; Charlop-Powers, Z.; van Wezel, G.P.; Medema, M.H.; Weber, T. antiSMASH 6.0: Improving cluster detection and comparison capabilities. Nucleic Acids Res. 2021. [CrossRef]

81. Singh, M.; Zannella, C.; Folliero, V.; Di Girolamo, R.; Bajardi, F.; Chianese, A.; Altucci, L.; Damasco, A.; Del Sorbo, M.R.; Imperatore, C.; et al. Combating Actions of Green 2D-Materials on Gram Positive and Negative Bacteria and Enveloped Viruses. Front. Bioeng. Biotechnol. 2020, 8, 569967. [CrossRef]

82. Romero, J.R.; Gross, T.; Abromowitch, M.; Jung, L. Pleconaril Treatment of Vaccine-Acquired Poliovirus. Pediatr. Res. 1999, 45, 173. [CrossRef]

83. Chambers, M.C.; Maclean, B.; Burke, R.; Amodei, D.; Ruderman, D.L.; Neumann, S.; Gatto, L.; Fischer, B.; Pratt, B.; Egertson, J.; et al. A cross-platform toolkit for mass spectrometry and proteomics. Nat. Biotechnol. 2012, 30, 918-920. [CrossRef] [PubMed]

84. Myers, O.D.; Sumner, S.J.; Li, S.; Barnes, S.; Du, X. One Step Forward for Reducing False Positive and False Negative Compound Identifications from Mass Spectrometry Metabolomics Data: New Algorithms for Constructing Extracted Ion Chromatograms and Detecting Chromatographic Peaks. Anal. Chem. 2017, 89, 8696-8703. [CrossRef]

85. Della Sala, G.; Mangoni, A.; Costantino, V.; Teta, R. Identification of the Biosynthetic Gene Cluster of Thermoactinoamides and Discovery of New Congeners by Integrated Genome Mining and MS-Based Molecular Networking. Front. Chem. 2020, 8, 397. [CrossRef]

86. Johnson, M.B.; Wen, Z. Production of Biodiesel Fuel from the Microalga Schizochytrium limacinum by Direct Transesterification of Algal Biomass. Energy Fuels 2009, 23, 5179-5183. [CrossRef] 